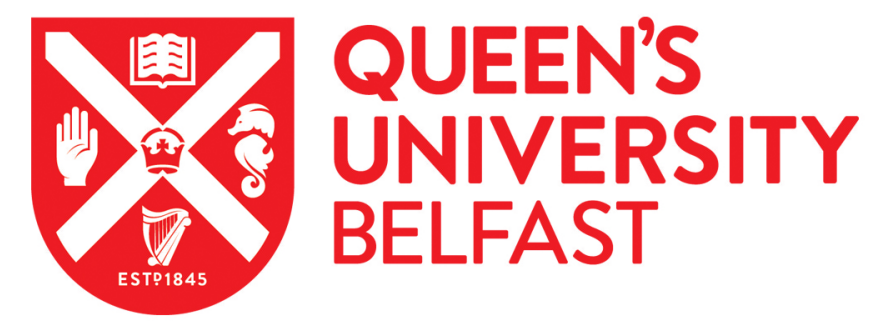

\title{
Effect of mixed anions on the transport properties and performance of an ionic liquid-based electrolyte for lithium-ion batteries
}

Chaudoy, V., Jacquemin, J., Tran-Van, F., Deschamps, M., \& Ghamouss, F. (2019). Effect of mixed anions on the transport properties and performance of an ionic liquid-based electrolyte for lithium-ion batteries. Pure and Applied Chemistry, 91(8), 1361-1381. https://doi.org/10.1515/pac-2018-1006

\section{Published in:}

Pure and Applied Chemistry

Document Version:

Publisher's PDF, also known as Version of record

Queen's University Belfast - Research Portal:

Link to publication record in Queen's University Belfast Research Portal

\section{Publisher rights}

Copyright 2019 the authors.

This is an open access article published under a Creative Commons Attribution-NonCommercial-NoDerivs License

(https://creativecommons.org/licenses/by-nc-nd/4.0/), which permits distribution and reproduction for non-commercial purposes, provided the

\section{General rights}

Copyright for the publications made accessible via the Queen's University Belfast Research Portal is retained by the author(s) and / or other copyright owners and it is a condition of accessing these publications that users recognise and abide by the legal requirements associated with these rights.

Take down policy

The Research Portal is Queen's institutional repository that provides access to Queen's research output. Every effort has been made to ensure that content in the Research Portal does not infringe any person's rights, or applicable UK laws. If you discover content in the Research Portal that you believe breaches copyright or violates any law, please contact openaccess@qub.ac.uk. 


\title{
Conference paper
}

\section{Victor Chaudoy, Johan Jacquemin, François Tran-Van, Michaël Deschamps* and Fouad Ghamouss* Effect of mixed anions on the transport properties and performance of an ionic liquid-based electrolyte for lithium-ion batteries}

https://doi.org/10.1515/pac-2018-1006

\begin{abstract}
In this work, the physical, transport and electrochemical properties of various electrolytic solutions containing the 1-propyl-1-methylpyrrolidinium bis[fluorosulfonyl]imide $\left(\left[\mathrm{C}_{3} \mathrm{C}_{1}\right.\right.$ pyr $\left.][\mathrm{FSI}]\right)$ mixed with the lithium bis[(trifluoromethyl)sulfonyl]imide (Li[TFSI]) over a wide range of compositions are reported as a function of temperature at atmospheric pressure. First, the ionicity, lithium transference number, and transport properties (viscosity and conductivity) as well as the volumetric properties (density and molar volume) were determined as a function of lithium salt concentration from 293 to $343 \mathrm{~K}$. Second, the self-diffusion coefficient of each ion in solution was measured by nuclear magnetic resonance (NMR) spectroscopy with pulsed field gradients (PFG). Moreover, an analysis of the collected nuclear Overhauser effect (NOE) data along with ab initio and COSMO-RS calculations was conducted to depict intra and intermolecular neighbouring within the electrolytic mixtures. Based on this analysis, and as expected, all activation energies increase with the Li[TFSI] concentration in solution, and all activation energies were determined from the self-diffusion data for all ions. Interestingly, regardless of the composition in solution, these activation energies were similar, except for those determined for the [FSI $]^{-}$anion. The activation energy of $[\mathrm{FSI}]^{-}$self-diffusion relatively decreases compared to the other ions as the lithium salt concentration increases. Furthermore, the lithium transference was strongly affected by the lithium salt concentration, reaching an optimal value and an ionicity of approximately $50 \%$ at a molality close to $0.75 \mathrm{~mol} \cdot \mathrm{kg}^{-1}$. Finally, these electrolytes were used in lithium-ion batteries (i.e. Li/NMC and LTO/NMC), demonstrating a clear relationship between the electrolyte formulation, its transport parameters and battery performance.
\end{abstract}

Keywords: batteries; ionic liquid; ISSP-18; lithium salt; NMR self-diffusion; nuclear Overhauser effect.

\section{Introduction}

The investigation of a novel electrolyte chemistry currently includes the great challenge of overcoming safety issues related to commonly used organic solvents in lithium batteries [1]. Indeed, benchmark electrolytes are

Article note: A collection of invited papers based on presentations at the $18^{\text {th }}$ International Symposium on Solubility Phenomena and Related Equilibrium Processes (ISSP-18), Tours, France, 15-20 July 2018.

\footnotetext{
*Corresponding authors: Michaël Deschamps, CNRS UPR 3079 CEMHTI, Orléans University, F-45100, Orléans, France; and RS2E, French Network for Electrochemical Energy Storage, FR CNRS 3459, F-80039 Amiens, France, e-mail: michael.deschamps@univ-orleans.fr; and Fouad Ghamouss, Laboratoire de Physico-Chimie des Matériaux et des Electrolytes pour l'Energie (PCM2E), Tours University, Parc de Grandmont, 37200, Tours, France, e-mail: ghamouss@univ-tours.fr Victor Chaudoy and François Tran-Van: Laboratoire de Physico-Chimie des Matériaux et des Electrolytes pour l'Energie (PCM2E), Tours University, Parc de Grandmont, 37200, Tours, France

Johan Jacquemin: Laboratoire de Physico-Chimie des Matériaux et des Electrolytes pour l'Energie (PCM2E), Tours University, Parc de Grandmont, 37200, Tours, France; and QUILL Research Centre, School of Chemistry and Chemical Engineering, Queen's University Belfast, BT9 5AG, Belfast, Northern Ireland
} 
unsatisfactory due to their high flammability and reactivity. Since the last decade, significant efforts have been made to improve electrolyte safety with different strategies, including the use of high boiling-temperature solvents, flame-retardant additives, and redox shuttles. In this context, ionic liquids (ILs) are considered to be potential, safe and stable candidates to be used during the electrolyte formulation [1]. To date, hundreds of combinations of organic cations, such as imidazolium, pyridinium, phosphonium, ammonium or pyrrolidinium derivatives, and anions such as the hexafluorophosphate $\left(\left[\mathrm{PF}_{6}\right]^{-}\right)$, tetrafluoroborate $\left(\left[\mathrm{BF}_{4}\right]^{-}\right)$, bis[(trifluoromethyl)sulfonyl]imide ([TFSI $\left.]^{-}\right)$, or bis[fluorosulfonyl]imide ([FSI $]^{-}$) have been used to form ILs with suitable properties, such as good ionic conductivity, a wide liquid range and a large electrochemical window, for battery applications [2-5].

Among these ILs, those containing the [FSI $]^{-}$anion exhibit higher conductivities and better diffusivities than their analogues based on [TFSI] $]^{-}$and have therefore attracted considerable attention $[6,7]$. Moreover, recent reports highlight the ability of [FSI] ${ }^{-}$to efficiently passivate anode materials in Li-ion batteries [8-10]. For example, over the last decade, several groups have investigated the utilization of 1-propyl-1-methylpyrrolidinium bis[fluorosulfonyl]imide, $\left(\left[\mathrm{C}_{3} \mathrm{C}_{1}\right.\right.$ pyr $\left.][\mathrm{FSI}]\right)$ as the main solvent during the formulation of electrolytes for lithium-ion batteries [11-13]. Furthermore, the fundamental and practical aspects of ionic diffusion and dissociation, conductivity, lithium transference and interactions between ions in IL-based electrolytes have been addressed by several groups using different ILs, including those based on pyrrolidinium, piperidinium or imidazolium cation [6, 14-16]. Such studies are fundamentally important since a prior knowledge of lithium-ion transport in electrolytic solutions is crucial for fine-tuning battery operations. In addition to the electrode composition or battery design, the choice of the electrolyte and its formulation affect also the battery performances (e.g. its capacity, energy, maximum power, etc.), which could be associated to the physical properties of the electrolytic solution. Indeed, the transport properties (including viscosity, ionic conductivity, lithium transference and diffusion) of the electrolyte can be related to battery performances, especially when a high charge/ discharge rate is applied. For example, Yoon et al. investigated electrolyte mixtures containing $\left[\mathrm{C}_{3} \mathrm{C}_{1}\right.$ pyr] $\left.] \mathrm{FSI}\right]$ and Li[FSI] and demonstrated that even at a high lithium salt concentration, good cycling performances in a Li/LiCoCO ${ }_{2}$ type battery could be achieved even under high rates of charge/discharge [17]. More recently, Rüther et al. also reported a study on the transport properties of the $\left[\mathrm{C}_{3} \mathrm{C}_{1} \mathrm{pyr}\right][\mathrm{FSI}]$ and Li[FSI] binary mixture highlighting the dramatic effect of the Li-salt concentration on these properties [6]. Furthermore, based on their results, these authors highlighted the absence of both ion associations and the possible dynamic behaviour of [FSI] ${ }^{-}$anion in this particular electrolytic solution. However, in these recent studies, the electrolyte (Li[FSI] mixed with $\left[\mathrm{C}_{3} \mathrm{C}_{1}\right.$ pyr] $[\mathrm{FSI}]$ ) contains a common and single anion, e.g. [FSI] ${ }^{-}$, and no conclusion on the impact of the anion structure on the electrolyte formulation, physical properties and interactions changes between all ions can be dressed, to date. All of them would be strongly affected by the selection of a lithium salt and an IL with different ions structure, and therefore the battery performances.

Among imide-based lithium salts reported in the literature, Li[TFSI] is certainly the most popular compound for Li-batteries applications mainly because battery-grade-purity Li[TFSI] salt is available from various suppliers at a larger and better price than the others, to date. Moreover, this interest is also driven by its higher anodic and thermal stability than Li[FSI] [18]. Furthermore, Li[TFSI] offers many advantages, such as a higher solubility in many solvents (including ILs), driven by a lower lattice energy than the benchmarks Li[PF $]$ or $\mathrm{Li}\left[\mathrm{BF}_{4}\right]$ [18]. Therefore, many studies investigating the use of IL-Li[TFSI] mixtures as electrolytes for Li-batteries have been reported [19-24]. However, only a few studies have been conducted by mixing salts to yield both [FSI] $^{-}$and [TFSI] $]^{-}$anions in solution. Among all these references, Kerner et al. [24] have investigated mixtures containing these two anions in solution by mixing Li[TFSI] salt and the 1-ethyl-3-methylimidazolium [FSI]-based IL. The authors highlighted that $\mathrm{Li}^{+}$is solvated by both [TFSI] ${ }^{-}$and [FSI]- in solution. More interestingly, this study also demonstrated that mixed anion electrolytes have anodic stabilities between 4.5 and $5.0 \mathrm{~V}$ vs. $\mathrm{Li}$, while anodic decomposition starts at $4.0 \mathrm{~V}$ vs. Li when using an electrolyte containing only [FSI] ${ }^{-}$.

During this work, electrolytes based on 1-propyl-1-methylpyrrolidinium bis[fluorosulfonyl]imide ([ $\mathrm{C}_{3} \mathrm{C}_{1}$ pyr] $[\mathrm{FSI}]$ ) mixed with lithium bis[(trifluoromethyl)sulfonyl]imide (Li[TFSI]) were characterized in term of their volumetric properties, viscosity, and ionic conductivity as a function of composition and temperature at atmospheric pressure. Furthermore, to better understand the interactions in solution, nuclear magnetic 
resonance (NMR) spectroscopy with pulsed field gradients (PFG), ab initio and COSMO-RS were used to highlight intra and intermolecular neighbouring in the electrolytic mixtures. Finally, the performance in lithiumion batteries was examined to provide reliable information on the influence of transport and intermolecular interactions on battery performances.

\section{Experimental}

\section{Materials and electrolyte preparation}

The high-purity IL 1-propyl-1-methylpyrrolidinium bis[fluorosulfonyl]imide, $\left(\left[\mathrm{C}_{3} \mathrm{C}_{1}\right.\right.$ pyr] $\left.][\mathrm{FSI}],>99.0 \%\right)$ and the lithium bis[(trifluoromethyl)sulfonyl]imide salt, (Li[TFSI], >99.0\%) were purchased from Solvionic, France. During this study, the selected IL was used after drying under high vacuum $(1 \mathrm{~Pa})$ at $343 \mathrm{~K}$ overnight and was then stored under nitrogen atmosphere inside an MBraun glove box to avoid moisture contamination.

Each electrolyte was then simply prepared by mixing known quantities of selected salts measured to an accuracy of $\pm 1 \cdot 10^{-4} \mathrm{~g}$ using an OHAUS pioneer ${ }^{\mathrm{TM}}$ balance under a dry atmosphere in an MBraun glove box with water content $<1 \mathrm{ppm}$ at $298.15 \mathrm{~K}$. During this study, several salt-in-salt mixtures, called electrolytes, were produced as a function of the composition of Li[TFSI] dissolved in $\left[\mathrm{C}_{3} \mathrm{C}_{1} \mathrm{pyr}\right][\mathrm{FSI}]$. Interestingly, at $298.15 \mathrm{~K}, \mathrm{Li}[\mathrm{TFSI}]$ is completely soluble in $\left[\mathrm{C}_{3} \mathrm{C}_{1}\right.$ pyr] [FSI] up to an equimolar composition, while a gel like solution is then obtained at higher Li-salt composition (i.e. as observed for a mixture based on a Li-salt and IL mole factions, $x_{\mathrm{LiTFSI}}=\frac{n_{\mathrm{Li}[\mathrm{TFSI}]}}{n_{\mathrm{Li}[\mathrm{TFSI}]}+n_{\mathrm{IC} \mathrm{C}_{3} \text { pyr }[\mathrm{FSII}]}}=0.613$ and $\left.x_{\mathrm{IL}}=1-x_{\mathrm{Li}[\mathrm{TFSI}]}=0.387\right)$. Herein, nine electrolytes based on the $\left(\left[\mathrm{C}_{3} \mathrm{C}_{1}\right.\right.$ pyr $\left.][\mathrm{FSI}]+\mathrm{Li}[\mathrm{TFSI}]\right)$ mixture were selected and prepared by mass at $298.15 \mathrm{~K}$ at a Li[TFSI] molality (e.g. $\mathrm{mol}_{\text {Li[TFSI] }}$ per $\mathrm{kg}_{\mathrm{IL}}$ ) close to $(0.0,0.075,0.448,0.747,0.971,1.195,1.419,1.867$ and 2.389$) \mathrm{mol} \cdot \mathrm{kg}^{-1}$, corresponding to a Li[TFSI] mole fraction, $x_{\mathrm{Li} \text { TTFII }}$, of approximately $(0.000,0.023,0.121,0.187,0.230,0.269,0.304$, 0.365 and 0.424$)$, respectively. Selected electrolytes were then stored inside the argon-filled glove box to avoid water contamination from the atmosphere during the entire study. The water content, which has remarkable effects on the physical properties of the salts and electrolytes $[25,26]$, was measured before and after any measurement through Karl-Fischer coulometric titration using a Metrohm 851 coulometer within an accuracy of nearly $\pm 0.3 \%$ in water mass content units. When testing the pure compounds or electrolytes, these measurements revealed very low levels of water with values always near $10 \mathrm{ppm}$, i.e. lower than $0.001 \mathrm{wt} \%$. The abbreviation, source, water content and molecular purity of each compound studied are reported in Table 1.

\section{Experimental methods}

The densities of the pure IL and selected electrolytes were determined by using an Anton Parr digital vibrating tube densimeter (model 60/602, Anton Parr, France) from 293 to $343 \mathrm{~K}$ with an accuracy of $\pm 0.01 \mathrm{~K}$. The densimeter was first calibrated at all temperatures with degassed water and dehumidified air at atmospheric pressure, as recommended by the manufacturer. Eleven readings were taken for each density measurement reported therein. The density of pure Li[TFSI] was calculated as a function of temperature by using the empirical equation reported by Gilbert et al. [27]. The standard uncertainties of the experimen-

Table 1: Source, abbreviation, purity, and water content for each chemical sample reported during this work.

\begin{tabular}{|c|c|c|c|c|}
\hline Chemical name & Source & Abbreviation & Mole fraction purity & Water content (ppm) \\
\hline 1-Propyl-1-methylpyrrolidinium bis[fluorosulfonyl]imide & Solvionic & {$\left[\mathrm{C}_{3} \mathrm{C}_{1} \mathrm{pyr}\right][\mathrm{FSI}]$} & $>0.99$ & $<10$ \\
\hline Lithium bis[(trifluoromethyl)sulfonyl]imide & Solvionic & $\mathrm{Li}[\mathrm{TFSI}]$ & $>0.99$ & $<10$ \\
\hline
\end{tabular}


tal density and of the calculated molar volume values were better than $10^{-4} \mathrm{~g} \cdot \mathrm{cm}^{-3}$ and $0.1 \mathrm{~cm}^{3} \cdot \mathrm{mol}^{-1}$, respectively.

An Anton Paar rolling-ball viscometer Lovis 2000 M/ME was then used to determine the viscosity $(\eta)$ of the pure IL and selected electrolytes at atmospheric pressure as a function of temperature from 293 to $343 \mathrm{~K}$ with an accuracy of nearly $\pm 0.02 \mathrm{~K}$. Ultrapure water was used to calibrate the viscometer. From this study, the relative uncertainty of the reported viscosity measurements did not exceed $\pm 2 \%$.

Conductivity measurements were performed by using a Crison GLP31 digital multi-frequency conductometer between 1000 and $5000 \mathrm{~Hz}$. The temperature was controlled between 263 and $343 \mathrm{~K}$ with an accuracy of $\pm 0.01 \mathrm{~K}$ by means of a JULABO thermostatic bath. The conductometer was first calibrated with standard solutions of known conductivity (i.e. 0.1 and $0.02 \mathrm{~mol} \cdot \mathrm{dm}^{-3} \mathrm{KCl}$ aqueous solutions). Each conductivity was recorded when its stability was better than $1 \%$ within $2 \mathrm{~min}$, and the relative uncertainty of the reported conductivities did not exceed $\pm 3 \%$.

\section{Self-diffusion coefficients, transference number and ion pairing determination - pulsed field gradient nuclear magnetic resonance (PFG-NMR)}

The lithium transference number $T_{\mathrm{Li}+}$ was determined using a lithium metal symmetrical cell. Cells were polarized with a constant voltage of $1.0 \mathrm{mV}$ until a steady-state current was reached (5-10 min). The cell impedance was measured before and after each to determine the cell resistance. Since the cell is reversible to only $\mathrm{Li}^{+}$, ion transport to reach the steady state results from only $\mathrm{Li}^{+}$motion between the two lithium electrodes. The transference number of $\mathrm{Li}^{+}, T_{\mathrm{Li}+}$, can then be calculated via Bruce and Vincent's method by using Eq. 1:

$$
T_{\mathrm{Li}+}=\mathrm{I}_{\mathrm{ss}} / \mathrm{I}_{0}
$$

where $\mathrm{I}_{\mathrm{sS}}$ is the steady-state current reached after cell polarization, and $\mathrm{I}_{0}$ is the initial current, which can be determined more accurately by using the cell resistance and Ohm's law.

All ${ }^{1} \mathrm{H},{ }^{19} \mathrm{~F}$ and ${ }^{7} \mathrm{Li}$ diffusion experiments were performed at a magnetic field strength of $17.6 \mathrm{~T}\left({ }^{1} \mathrm{H}\right.$ Larmor frequency of $750 \mathrm{MHz}$ ) on a Bruker Avance $\mathrm{HD}$ wide-bore spectrometer using a double-channel ${ }^{1} \mathrm{H}{ }^{-19} \mathrm{~F} /{ }^{31} \mathrm{P}-{ }^{15} \mathrm{~N}$ 3.2 mm Bruker MAS probe inserted in a Micro 2.5 XYZ gradient system with $60 \mathrm{~A}$ amplifiers. ${ }^{7} \mathrm{Li}^{-19} \mathrm{~F}$ Heteronuclear Overhauser Effect SpectroscopY experiments (HOESY) were performed using the same conditions. All experiments were recorded at a regulated temperature using a $1000 \mathrm{~L} \cdot \mathrm{h}^{-1}$ flux of dried air with a $173 \mathrm{~K}$ dew point using the Bruker BVT unit, and the temperature calibration was obtained with the ${ }^{1} \mathrm{H}$ NMR spectra of methanol [28].

Self-diffusion coefficients (D) were obtained for $\left[\mathrm{C}_{3} \mathrm{C}_{1} \mathrm{pyr}\right]^{+}$, [FSI $]^{-},[\mathrm{TFSI}]^{-}$and $\mathrm{Li}^{+}$using the ${ }^{1 \mathrm{H}},{ }^{19} \mathrm{~F}$ and ${ }^{7} \mathrm{Li}$ spins. The pulsed field gradient-stimulated echo pulse sequence was used with bipolar gradient pulses and a longitudinal eddy-current delay (STE-BP-LED) [29].

The maximum gradient value was between 50 and $150 \mathrm{G} \cdot \mathrm{cm}^{-1}$ with a sinusoidal gradient pulse effective duration $\delta=2-5 \mathrm{~ms}$ and diffusion delays of $\Delta=50-200 \mathrm{~ms}$. No convection effect was detected using a double stimulated echo sequence for convection compensation [30], as the sample is inside a small $3.2 \mathrm{~mm}$ rotor (filled with an ionic liquid electrolyte solution in an argon glove box).

The echo attenuation curves were fitted in the Bruker Topspin software using the Stejskal-Tanner equation (Eq. 2):

$$
\mathrm{I}(\mathrm{g})=\mathrm{I}_{0} \exp \left[-\mathrm{D}(2 \gamma \mathrm{g} \delta)^{2}(\Delta-\delta / 3)\right]
$$

where $\mathrm{I}(\mathrm{g})$ is the observed signal intensity, $\mathrm{I}_{0}$ is the maximum signal intensity, $\gamma$ is the gyromagnetic ratio of the observed nucleus, $\mathrm{g}$ is the gradient strength, $\delta$ is the gradient pulse duration, and $\Delta$ is the diffusion delay between the gradient pulses. 
The Overhauser magnetization transfer from ${ }^{7} \mathrm{Li}$ to ${ }^{19} \mathrm{~F}$ spins was demonstrated using one or two-dimensional HOESY experiments for ${ }^{7} \mathrm{Li}$ to ${ }^{19} \mathrm{~F}$ and ${ }^{19} \mathrm{~F}$ to ${ }^{7} \mathrm{Li}$ transfer, respectively, at a magnetic field strength of 17.6 $\mathrm{T}$ [31]. The delay for magnetization recovery (1 s) was sufficient to ensure the recovery of ${ }^{7} \mathrm{Li}$ or ${ }^{19} \mathrm{~F}$ magnetization, the $\mathrm{T}_{1}$ values of which are approximately $900 \mathrm{~ms}, 150 \mathrm{~ms}$ and $400 \mathrm{~ms}$ for ${ }^{7} \mathrm{Li}$, [FSI] ${ }^{-}$and [TFSI] ${ }^{-}$, respectively. The delay used for magnetization transfer was set to $100 \mathrm{~ms}$. The $1 \mathrm{D}{ }^{7} \mathrm{Li}$ to ${ }^{19} \mathrm{~F}$ transfer required 65536 transients for a good signal to noise ratio, while the $2 \mathrm{D}^{19} \mathrm{~F}$ to ${ }^{7} \mathrm{Li}$ required 128 transients and $256 \mathrm{t}_{1}$ increments with the States mode in the second dimension.

The Nernst-Einstein equation (Eq. 3) was applied to calculate the molar conductivity $\left(\Lambda_{\mathrm{NMR}}\right)$ from the PGSE-NMR diffusion coefficients:

$$
\Lambda_{\mathrm{NMR}}=\mathrm{N}_{\mathrm{A}} \mathrm{e}^{2}\left(\mathrm{D}_{\text {cation }}+\mathrm{D}_{\text {anion }}\right) / \mathrm{kT}=\mathrm{F}^{2}\left(\mathrm{D}_{\text {[CIC3pyr] }}{ }^{+}+\mathrm{D}_{\mathrm{Li}}{ }^{+}+\mathrm{D}_{[\text {[FSI] }}^{-}+\mathrm{D}_{[\text {[TFSI] }}^{-}\right) / \mathrm{RT}
$$

where $\mathrm{N}_{\mathrm{A}}$ is Avogadro's number, e is the elementary electric charge, $\mathrm{F}$ is Faraday's constant, $\mathrm{R}$ is the gas constant, and $\mathrm{D}$ is the diffusion coefficient determined by PGSE-NMR.

\section{Battery performances}

Li-ion batteries were assembled in a coin-cell format (CR2032) using an aluminium foil coated with a lithium nickel manganese cobalt oxide ( $\left.\mathrm{LiNi}_{0.33} \mathrm{Mn}_{0.33} \mathrm{Co}_{0.33} \mathrm{O}_{2}, \mathrm{NMC}\right)$ as the cathode (Sigma-Aldrich) and a lithium foil or aluminium foil coated with lithium titanate $\left(\mathrm{Li}_{4} \mathrm{Ti}_{5} \mathrm{O}_{12}\right.$, Sigma-Aldrich) as the anode. The average active material mass are $14.1 \mathrm{mg} / \mathrm{cm}^{2}$ and $13.6 \mathrm{mg} / \mathrm{cm}^{2}$ respectively for NMC and LTO electrode. A porous Whatman ${ }^{\circledR}$ glass microfibre membrane (thickness $\eta=675 \mu \mathrm{m}$ and pore diameter $\emptyset=2.7 \mu \mathrm{m}$ ) filled with the electrolyte solution was used as the separator. The electrochemical characterization of the Li-ion batteries was conducted using constant current charging and discharging at different current rates from $\mathrm{C} / 20$ to $1 \mathrm{C}$ rates. The specific capacity was determined with respect to the weight of active materials (NMC) in the cathode. Charge/ discharge tests were performed using cut-off voltages of $4.2 \mathrm{~V}$ (charge) and $3.0 \mathrm{~V}$ (end of discharge) in the case of Li/NMC coin-cell testing, while the cut-of voltages were $1.6 \mathrm{~V}$ (end of discharge) and $2.8 \mathrm{~V}$ (end of charge) when the LTO/NMC configuration was used. Electrochemical measurements were carried-out on a Versatile Multichannel Potentiostat (Biologic S.A).

\section{Predictive methods}

Calculations of the sigma surface and structure descriptors, such as the COSMO surface and volume, were completed using the Turbomole 7.0 programme package [32]. Before being able to visualize the 3D structure of each species using TmoleX (version 4.1.1), all structures were optimized in the gas phase with a convergence criterion of $10^{-8}$ Hartree, using HF- $6311 \mathrm{G}^{\star \star}++$ basis set, followed by DFT calculations combining the resolution of identity (RI) approximation [33, 34], within the Turbomole 7.0 programme package using the B3LYP function with the def2-TZVP basis set [35-37]. The resulting optimized structures were then used as inputs in the COSMOconfX programme (version 4.0) to generate the conformers of each species using the BP-TZVPD-FINE-COSMO + GAS basis set. The COSMO surface $\left(\AA^{2}\right)$ and volume $\left(\AA^{3}\right)$ as well as the sigma surface of each species was then determined and viewed using the COSMOthermX software, which is based on the COSMO-RS (COnductor-like Screening MOdel) computation technique. The combination of TmoleX and COSMOthermX software (version C30 16.02) was then used to understand the differences in structure, charge distribution and volume of the two salts investigated during this study and to understand their interactions in solution by following the methodology previously described by our group [38-40]. 


\section{Results and discussion}

\section{Volumetric properties of selected electrolytes}

\section{Effects of composition and temperature on electrolyte density}

The density of pure $\left[\mathrm{C}_{3} \mathrm{C}_{1}\right.$ pyr $][\mathrm{FSI}]$ and of selected electrolytes was measured as a function of temperature from 293 to $343 \mathrm{~K}$ at atmospheric pressure. The experimental data obtained here are presented in Table S1 of the electronic supporting information (ESI) and are shown in Fig. 1. The measured density data of pure $\left[\mathrm{C}_{3} \mathrm{C}_{1}\right.$ pyr] [FSI] ranges from 1.30 to $1.35 \mathrm{~g} \cdot \mathrm{cm}^{-3}$ from 293 to $343 \mathrm{~K}$, decreasing, as expected, when the temperature increases. A similar trend is also observed in the case of the investigated electrolytes. In Table S1 of the ESI, one can see that the hypothetical density of pure Li[TFSI], which was calculated as a function of the temperature using the equation reported by Gilbert et al. [27], is denser than pure $\left[\mathrm{C}_{3} \mathrm{C}_{1}\right.$ pyr][FSI] and the electrolytes investigated in this study. In other words, the density of investigated Li[TFSI]-based electrolytes increases with the salt concentration in solution. Furthermore, as shown in Fig. 1, a linear relationship can be used to fit the electrolyte density data as a function of Li-salt composition, expressed in Li[TFSI] mole fraction, for each isotherm. Each individual parameter of both fitting processes is reported in Tables S2 and S3 of the ESI along with their calculated standard deviations. Due to the linear relationship between density and the Li-salt composition in solution, the density, $\rho$, can then be evaluated for a given composition from $x_{\mathrm{Li}[\mathrm{TFSI}]}=0$ to $x_{\mathrm{Li}[\mathrm{TFSI}]}=0.424$.

Because the dependence of temperature on the density of the pure $\left[\mathrm{C}_{3} \mathrm{C}_{1} \mathrm{pyr}\right][\mathrm{FSI}]$ was already determined by other groups, we could directly compare our experimental data with the data available in the literature as a function of temperature [6, 41-44]. The experimental $\left[\mathrm{C}_{3} \mathrm{C}_{1}\right.$ pyr] $[\mathrm{FSI}]$ density dataset reported herein was assessed with those available in the literature using the relative absolute average deviation, RAAD (Eq. 4):

$$
100 \cdot \operatorname{RAAD}=\frac{1}{N}\left|\frac{Y_{\text {lit. }}-Y_{\text {exp. }}}{Y_{\text {lit. }}}\right|=\frac{1}{N}|\delta|
$$

where $N$ is the total number of data points, $Y_{\text {exp. }}$ and $Y_{\text {lit. }}$ are the experimental and literature data for the studied properties, respectively, and $\delta$ is the relative deviation between the experimental and literature data.

As shown in Fig. S1 of the ESI, excellent agreement is observed among the data reported by Rüther et al. $(\mathrm{RAAD}=0.01 \%)$ [6], Tagiuri et al. $(\mathrm{RAAD}=0.02 \%)$ [41], Matsumoto et al. (RAAD $=0.07 \%)$ [42], Seki et al. $(\mathrm{RAAD}=0.09 \%)$ [43], and Hayamizu et al. $(\mathrm{RAAD}=0.10 \%)$ [44], over the whole temperature range covered in this work.

a

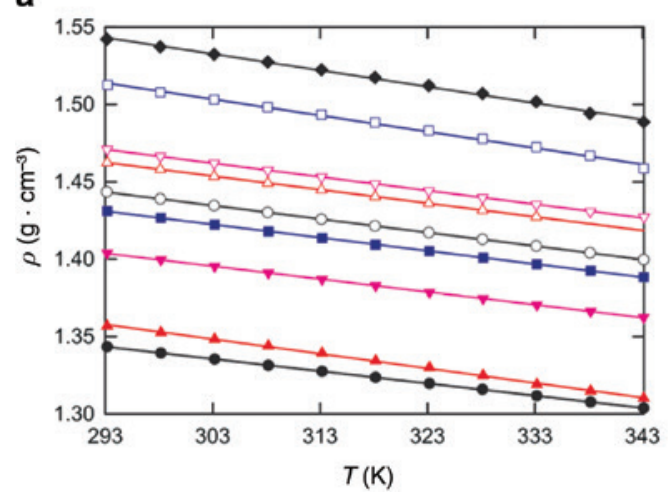

b

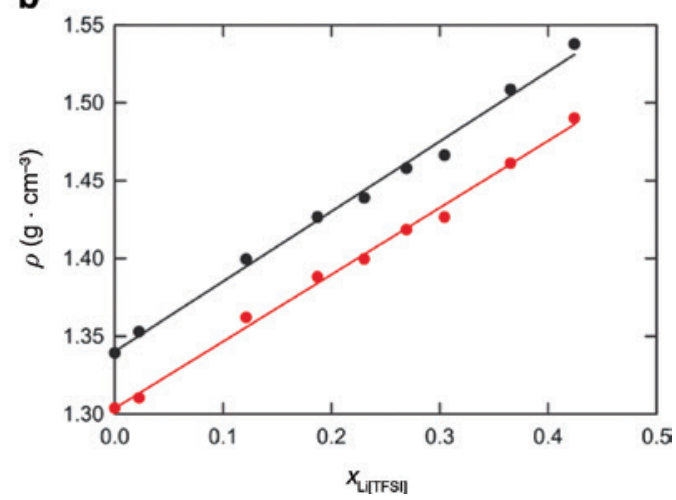

Fig. 1: (a) Density of selected ([ $\mathrm{C}_{3} \mathrm{C}_{1}$ pyr $\left.][\mathrm{FSI}]+\mathrm{Li}[\mathrm{TFSI}]\right)$ electrolytes at atmospheric pressure as a function of temperature at the following Li[TFSI] mole fraction: $\bullet, 0$ (pure $\left[\mathrm{C}_{3} \mathrm{C}_{1}\right.$ pyr][FSI]); $\Delta, 0.023 ; \nabla, 0.121 ; \mathbf{\square}, 0.187 ; 0,0.230 ; \triangle, 0.269 ; \nabla, 0.304 ; \square, 0.365$; $\bullet, 0.424$. (b) Density as function of the Li[TFSI] mole fraction at: $\bullet, 298.15 \mathrm{~K}$ and $\bullet, 343.15 \mathrm{~K}$. 


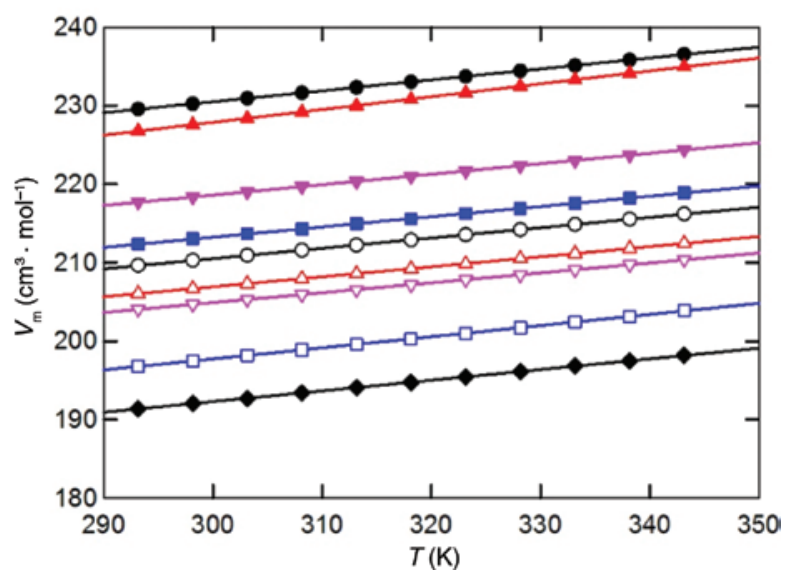

Fig. 2: Molar volume of selected ([ $\mathrm{C}_{3} \mathrm{C}_{1}$ pyr $\left.][\mathrm{FSI}]+\mathrm{Li}[\mathrm{TFSI}]\right)$ electrolytes at atmospheric pressure as a function of temperature at the following Li[TFSI] mole fraction: $\bullet, 0$ (pure $\left[\mathrm{C}_{3} \mathrm{C}_{1}\right.$ pyr][FSI]); $\Delta, 0.023 ; \nabla, 0.121 ; \mathbf{\square}, 0.187 ; 0,0.230 ; \triangle, 0.269 ; \nabla, 0.304$; $\square, 0.365 ; \diamond, 0.424$.

\section{Molar volumes}

Herein, we report the volumetric properties of the $\left(\left[\mathrm{C}_{3} \mathrm{C}_{1}\right.\right.$ pyr $\left.][\mathrm{FSI}]+\mathrm{Li}[\mathrm{TFSI}]\right)$ binary mixture as a function of temperature and composition up to a $x_{\mathrm{Li}[\mathrm{TFSI}]}$ value of nearly 0.424 . The molar volumes, $V_{\mathrm{m}}$, of the pure $\left[\mathrm{C}_{3} \mathrm{C}_{1}\right.$ pyr] [FSI] and investigated electrolytes are calculated as:

$$
V_{\mathrm{m}, \mathrm{i}}=\frac{M_{\mathrm{i}}}{\rho_{\mathrm{i}}}
$$

where $M_{\mathrm{i}}$ and $\rho_{\mathrm{i}}$ are the molar mass and density of the studied compound, respectively.

Equation 5 was also used to determine the molar volume of pure Li[TFSI] by using the hypothetical density equation reported by Gilbert et al. [27] as a function of temperature.

The calculated molar volumes are reported in Table S4 of the ESI as function of temperature up to $343.15 \mathrm{~K}$. In this study, the molar volumes of the pure $\left[\mathrm{C}_{3} \mathrm{C}_{1} \mathrm{pyr}\right][\mathrm{FSI}]$ and investigated electrolytes appear to increase with the temperature, as expected. For example, molar volumes of approximately 229.6 and $236.5 \mathrm{~cm}^{3} \cdot \mathrm{mol}^{-1}$ are observed in the case of pure $\left[\mathrm{C}_{3} \mathrm{C}_{1}\right.$ pyr $][\mathrm{FSI}]$ at 293.15 and $343.15 \mathrm{~K}$, respectively. Furthermore, due to the difference in their molecular weights, the molar volume of pure $\left[\mathrm{C}_{3} \mathrm{C}_{1}\right.$ pyr] $[\mathrm{FSI}]\left(\mathrm{e} . \mathrm{g} .229 .6 \mathrm{~cm}^{3} \cdot \mathrm{mol}^{-1}\right.$ at $293.15 \mathrm{~K}$ ) is larger than that calculated for pure Li[TFSI] (e.g. $151.0 \mathrm{~cm}^{3} \cdot \mathrm{mol}^{-1}$ at $293.15 \mathrm{~K}$ ). This demonstrates that the molar volume of the selected electrolytes decreases with the Li salt composition regardless of temperature, as shown in Fig. 2.

\section{Transport properties of selected electrolytes}

\section{Effects of the composition and temperature on electrolyte viscosity}

The viscosities of pure $\left[\mathrm{C}_{3} \mathrm{C}_{1} \mathrm{pyr}\right][\mathrm{FSI}]$ and the selected electrolytes was first investigated from 293 to $343 \mathrm{~K}$; the viscosities are reported herein in Table S5 of the ESI and are shown in Fig. 3a.

As expected, the viscosity of pure $\left[\mathrm{C}_{3} \mathrm{C}_{1}\right.$ pyr $][\mathrm{FSI}]$ decreases with temperature, typically from $48.8 \mathrm{mPa} \cdot \mathrm{s}$ at $293.15 \mathrm{~K}$ to $13.0 \mathrm{mPa} \cdot \mathrm{s}$ at $343.15 \mathrm{~K}$. In other words, as expected, $\left[\mathrm{C}_{3} \mathrm{C}_{1} \mathrm{pyr}\right][\mathrm{FSI}]$ is less viscous than [ $\mathrm{C}_{3} \mathrm{C}_{1}$ pyr] [TFSI] $(76.4 \mathrm{mPa} \cdot \mathrm{s}$ at $293.15 \mathrm{~K})$ [44], [C ${ }_{3} \mathrm{C}_{1}$ pyr] [BETI] $(200 \mathrm{mPa} \cdot \mathrm{s}$ at $293.15 \mathrm{~K})$ [45], and $\left[\mathrm{C}_{4} \mathrm{C}_{1} \mathrm{pyr}\right][\mathrm{FSI}]$ $(64.1 \mathrm{mPa} \cdot \mathrm{s}$ at $293.15 \mathrm{~K}$ ) [46]. A numerous previous studies found in the literature reported the viscosity of the $\left[\mathrm{C}_{3} \mathrm{C}_{1} \mathrm{pyr}\right][\mathrm{FSI}]$ [47-49]; however, very few provide numerical viscosity values for proper comparison. 
a

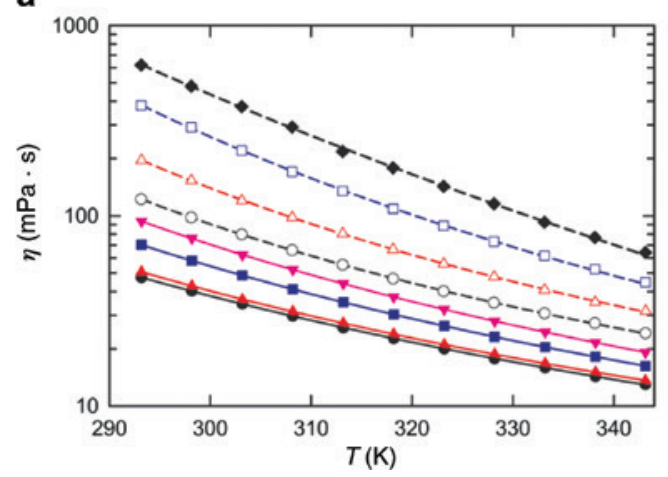

b

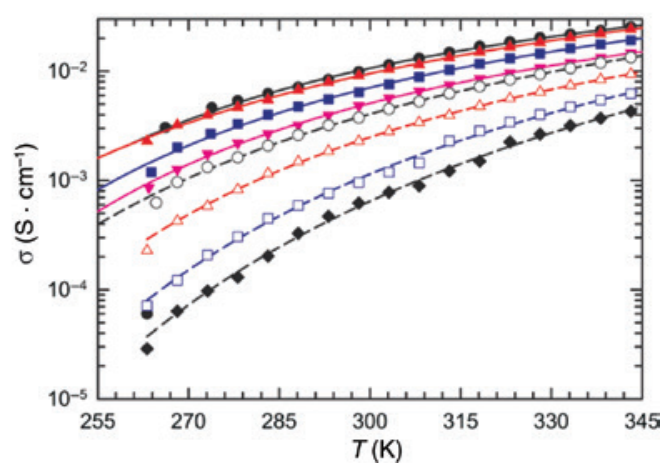

Fig. 3: Viscosity (a) and conductivity (b) of selected ([ $\mathrm{C}_{3} \mathrm{C}_{1}$ pyr $\left.][\mathrm{FSI}]+\mathrm{Li}[\mathrm{TFSI}]\right)$ electrolytes at atmospheric pressure as a function of temperature at the following Li[TFSI] mole fraction: $\bullet, 0$ (pure $\left[C_{3} C_{1}\right.$ pyr] $\left.[F S I]\right) ; \Delta, 0.023 ; \nabla, 0.121 ; \square, 0.187 ; 0,0.230 ; \triangle, 0.269$; $\nabla, 0.304 ; \square, 0.365 ; \diamond, 0.424$.

A comparison between the experimental viscosities of $\left[\mathrm{C}_{3} \mathrm{C}_{1} \mathrm{pyr}\right][\mathrm{FSI}]$ measured in this work and from literature sources that provide numerical viscosity data at atmospheric pressure $[6,41,44]$ shows that the reported data lie in the $\pm 1 \%$ range for most sources and temperatures investigated therein. For example, at $298.15 \mathrm{~K}$, viscosities of $41.35,41$ and $41.4 \mathrm{mPa} \cdot \mathrm{s}$ for $\left[\mathrm{C}_{3} \mathrm{C}_{1}\right.$ pyr] [FSI] were reported by Rüther et al. [6], Matsumoto et al. [42], and Hayamizu et al. [44], respectively. These viscosity values are in excellent agreement with that reported herein, e.g. $41.26 \mathrm{mPa} \cdot \mathrm{s}$ at $298.15 \mathrm{~K}$. In Fig. 3a, a regular incremental change in the viscosity of the solution is observed with increasing salt concentrations at a fixed temperature, and the viscosity increases with the mole fraction of salt, as expected. For example, at $298.15 \mathrm{~K}$ the ionic solutions containing a Li[TFSI] mole fraction, $x_{\mathrm{Li}[\mathrm{TFSI}]}=(0.121,0.187,0.365$, and 0.424) have viscosities of (58.0, 76.2, 292 and 480) $\mathrm{mPa} \cdot \mathrm{s}$, respectively, while a viscosity of approximately $41.3 \mathrm{mPa} \cdot \mathrm{s}$ was observed for pure $\left[\mathrm{C}_{3} \mathrm{C}_{1} \mathrm{pyr}\right][\mathrm{FSI}]$. Furthermore, an analysis of the data reported by Rüther et al. [6], and the values reported herein shows that the viscosity of the $\left[\mathrm{C}_{3} \mathrm{C}_{1}\right.$ pyr $][\mathrm{FSI}]$ - Li[TFSI]-based electrolyte seems to be slightly higher than that of $\left[\mathrm{C}_{3} \mathrm{C}_{1} \mathrm{pyr}\right][\mathrm{FSI}]-\mathrm{Li}[\mathrm{FSI}]$. For example, at $298.15 \mathrm{~K}$, the viscosity of the $\left(\left[\mathrm{C}_{3} \mathrm{C}_{1} \mathrm{pyr}\right][\mathrm{FSI}]+\mathrm{Li}[\mathrm{TFSI}]\right)$ mixture is close to $58.0,76.2$ or $98.0 \mathrm{mPa} \cdot \mathrm{s}$ at a Li[TFSI] mole fraction, $x_{\mathrm{Li}[\mathrm{TFSI}]}=(0.121,0.187$ or 0.230$)$, respectively, while, in the case of $\left[\mathrm{C}_{3} \mathrm{C}_{1}\right.$ pyr] $[\mathrm{FSI}]-\mathrm{Li}[\mathrm{FSI}]$ mixture, viscosity values close to 61.22 and $90.23 \mathrm{mPa} \cdot \mathrm{s}$ were reported by Rüther et al. [6] at $x_{\mathrm{Li} \text { [FSI] }}=(0.1292$ and 0.2288$)$, respectively. This result is expected because the viscosity data of [FSI]--based solutions are generally lower than those observed for [TFSI]-- or [BETI]--based electrolytes or pure ILs [44-46].

\section{Effects of the composition and temperature on electrolyte conductivity}

The temperature dependence on the conductivity of pure $\left[\mathrm{C}_{3} \mathrm{C}_{1} \mathrm{pyr}\right][\mathrm{FSI}]$ and selected electrolytes was then investigated from $255 \mathrm{~K}$ to $343 \mathrm{~K}$ by increasing the temperature and are reported herein in Table S6 of the ESI and shown in Fig. 3b.

The conductivity of selected solutions increases with temperature, ranging typically from 3.04 to $25.5 \mathrm{mS} \cdot \mathrm{cm}^{-1}$ for $\left[\mathrm{C}_{3} \mathrm{C}_{1}\right.$ pyr] $[\mathrm{FSI}]$ from 266.15 to $343.15 \mathrm{~K}$, respectively. Furthermore, as shown in Table $\mathrm{S} 7$ of the ESI, in the case of pure $\left[\mathrm{C}_{3} \mathrm{C}_{1} \mathrm{pyr}\right][\mathrm{FSI}]$, a large decrease in conductivity observed at temperatures below $267.15 \mathrm{~K}$ could be associated with the phase transition from solid to liquid. This result is in agreement with the melting temperature $\left(T_{\mathrm{m}}=265 \mathrm{~K}\right.$ [42], or $T_{\mathrm{m}}=267.55 \mathrm{~K}$ [47]) reported in the literature for this particular compound. A comparison between the experimental conductivities of $\left[\mathrm{C}_{3} \mathrm{C}_{1} \mathrm{pyr}\right][\mathrm{FSI}]$ measured in this work and those in the literature shows that the conductivities reported herein are generally higher with a maximum deviation generally observed at higher temperatures (i.e. $343.15 \mathrm{~K}$ ), with up to $1.6,3.0$, and $5.2 \mathrm{mS} \cdot \mathrm{cm}^{-1}$ observed in the data published by Rüther et al. [6], Matsumoto et al. [42], and Hayamizu et al. [44], respectively. Figure 3b shows that the conductivity of the solution decreases with salt concentration at a fixed temperature, as expected. 
For example, at $298.15 \mathrm{~K}$ the ionic solutions containing a Li[TFSI] mole fraction, $x_{\mathrm{Li}[\mathrm{TFSI}]}=0.121,0.187,0.365$, and 0.424 have a conductivity of $6.41,4.81,0.96$ and $0.62 \mathrm{mS} \cdot \mathrm{cm}^{-1}$, respectively, while a conductivity of approximately $9.89 \mathrm{mS} \cdot \mathrm{cm}^{-1}$ is observed for pure $\left[\mathrm{C}_{3} \mathrm{C}_{1} \mathrm{pyr}\right][\mathrm{FSI}$. With a similar approach to that used for the viscosity, the analysis of data reported by Rüther et al. [6], and those reported herein shows that the conductivity of the $\left[\mathrm{C}_{3} \mathrm{C}_{1}\right.$ pyr $][\mathrm{FSI}]$ - Li[TFSI]-based electrolyte is slightly lower than that of $\left[\mathrm{C}_{3} \mathrm{C}_{1}\right.$ pyr $][\mathrm{FSI}]-\mathrm{Li}[\mathrm{FSI}]$. For example, at $298.15 \mathrm{~K}$, the conductivity of the $\left(\left[\mathrm{C}_{3} \mathrm{C}_{1}\right.\right.$ pyr $\left.][\mathrm{FSI}]+\mathrm{Li}[\mathrm{TFSI}]\right)$ mixture is close to $6.41,4.81$, and $3.75 \mathrm{mS} \cdot \mathrm{cm}^{-1}$ at $x_{\mathrm{Li}[\mathrm{TFII}}=0.121,0.187$ and 0.230 , respectively. While in the case of $\left[\mathrm{C}_{3} \mathrm{C}_{1} \mathrm{pyr}\right][\mathrm{FSI}]-\mathrm{Li}[\mathrm{FSI}]$ mixture, Rüther et al. [6], reported values of 5.529 and $3.867 \mathrm{mS} \cdot \mathrm{cm}^{-1}$ at $x_{\mathrm{Li}[\mathrm{FSI}]}=0.1292$ and 0.2288 , respectively. This result is also expected, as the conductivity data of [FSI] --based solutions are generally higher than those observed for [TFSI] ${ }^{-}$- or [BETI] --based electrolytes or pure ILs [44-46].

\section{Effects of the composition and temperature on electrolyte ionicity}

Prior to reporting the selected solutions in a Walden-plot, the dependencies of temperature on the density, viscosity and conductivity were fitted using the following equations:

$$
\rho=a+b \cdot T
$$

where $a$ and $b$ are the fitting parameters.

$$
\begin{array}{cc}
\sigma=\sigma_{0} \exp \left[\frac{-E_{a}^{\sigma}}{R T}\right] & \eta=\eta_{0} \exp \left[\frac{E_{a}^{\eta}}{R T}\right] \\
\sigma=\sigma_{0} \exp \left[\frac{-B_{\sigma}}{T-T_{0}}\right] & \eta=\eta_{0} \exp \left[\frac{B_{\eta}}{T-T_{0}}\right]
\end{array}
$$

where $\eta_{0}, \sigma_{0}, B_{\eta}, B_{\sigma},\left(B_{i}=E_{a} / R\right)$, and $T_{0}$, are the fitting parameters of the Arrhenius and Vogel-Tamman-Fulcher (VTF) equations.

For each solution, the best-fitting parameters for density, viscosity and conductivity as a function of temperature are reported in Tables S2 and S7 of the ESI, together with the correlation coefficient for each fit.

The temperature dependences on the density, conductivity and viscosity for each solution studied herein are presented in Figs. 1, 3a and b, respectively. For the transport properties, according to such a correlation analysis (see Table S7 of the ESI), the temperature dependence of these properties are more correctly fitted by using the VTF equation (Eq. 8) than the Arrhenius law (Eq. 7), as expected [39].

A classical Walden rule diagram was then used to determine the ionicity of pure $\left[\mathrm{C}_{3} \mathrm{C}_{1}\right.$ pyr $][\mathrm{FSI}]$ and electrolytes. From that the ionic mobilities were represented through the equivalent conductivity, $\Lambda=V_{\mathrm{m}} \sigma$ $\left(\mathrm{S} \cdot \mathrm{cm}^{2} \cdot \mathrm{mol}^{-1}\right)$, as function of fluidity $\left(\right.$ Poise $\left.^{-1}\right)$ of the medium, $\phi=1 / \eta$, which is related to the ion mobility [50]. Figure 4 shows the variation of $\log (\Lambda)$ vs. $\log (1 / \eta)$ at various temperatures from 293.15 to $343.15 \mathrm{~K}$ for selected solutions containing $\left[\mathrm{C}_{3} \mathrm{C}_{1}\right.$ pyr $][\mathrm{FSI}]$ mixed with Li[TFSI]. According to the Walden rule, the ideal line represents fully dissociated ionic solutions having ions of equal mobility, such as aqueous $\mathrm{KCl}$ solutions at high dilution [51]. The pure $\left[\mathrm{C}_{3} \mathrm{C}_{1} \mathrm{pyr}\right][\mathrm{FSI}]$ is localized in the "good" IL zone of the Walden representation within a Walden product, $\mathrm{W}=\Lambda \eta=0.94 \mathrm{~S} \cdot \mathrm{P} \cdot \mathrm{cm}^{2} \cdot \mathrm{mol}^{-1}$ at $293.15 \mathrm{~K}$, which agrees well with the values reported in the literature $[6,47]$. Furthermore, all electrolytes investigated herein could also be considered "good"; however, the Fig. 4 shows that the Walden product of the solution decreases strongly with an increasing Li[TFSI] concentration. For example, at $293.15 \mathrm{~K}$ the ionic solutions containing a mole fraction of Li[TFSI] of $0.121,0.187,0.365$, and 0.424 have a Walden product close to $0.84,0.79,0.58$ and 0.57 $\mathrm{S} \cdot \mathrm{P} \cdot \mathrm{cm}^{2} \cdot \mathrm{mol}^{-1}$, respectively. This observation is certainly driven by different conduction mechanisms and structural changes in the solution, which are strongly affected by the composition of Li[TFSI] used during the formulation of a given electrolyte. This mechanism may also be related to the self-diffusivity of the ions in solution. 


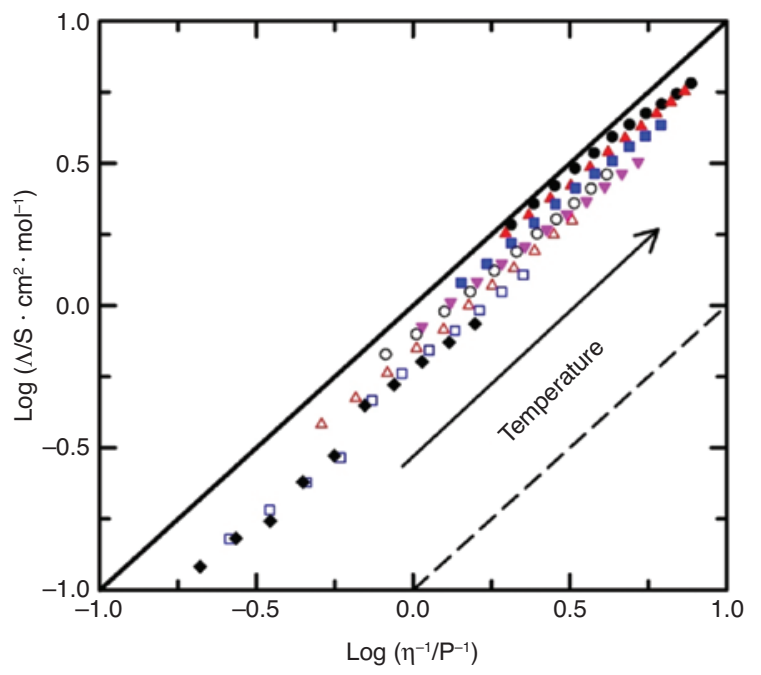

Fig. 4: Walden plot of selected ( $\left[\mathrm{C}_{3} \mathrm{C}_{1}\right.$ pyr $\left.][\mathrm{FSI}]+\mathrm{Li}[\mathrm{TFSI}]\right)$ electrolytes at atmospheric pressure as a function of temperature at the following Li[TFSI] mole fraction: $\bullet, 0$ (pure $\left[C_{3} C_{1}\right.$ pyr] $\left.[F S I]\right) ; \Delta, 0.023 ; \nabla, 0.121 ; \boldsymbol{\square}, 0.187 ; 0,0.230 ; \triangle, 0.269 ; \nabla, 0.304$; $\square, 0.365 ; \diamond, 0.424$. The dashed line represents a Walden product of $0.1 \mathrm{~S} \cdot \mathrm{P} \cdot \mathrm{cm}^{2} \cdot \mathrm{mol}^{-1}$ beneath which a solution is considered poorly ionic.

\section{Effects of the composition and temperature on electrolyte diffusivity}

The self-diffusion coefficients measured by NMR are shown in Fig. 5 at room temperature as a function of Li[TFSI] concentration expressed in Li-salt molality. As expected, the self-diffusion coefficient of each species decreases notably when the concentration of Li[TFSI] increases in solution. This behaviour is driven by the strongly polarizing lithium ion, which is the slowest diffusing species because it forms various complexes with anions in solution. Interestingly, the self-diffusion coefficients of selected ions in both former salts $\left.\left(\left[\mathrm{C}_{3} \mathrm{C}_{1} \text { pyr }\right]^{+} \text {and }[\mathrm{FSI}]^{-} \text {vs. } \mathrm{Li}^{+} \text {and [TFSI }\right]^{-}\right)$seem to be identical particularly when the $\mathrm{Li}[\mathrm{TFSI}]$ concentration is higher than $0.971 \mathrm{~mol} \cdot \mathrm{kg}^{-1}$, thus highlighting strong interactions between $\left[\mathrm{C}_{3} \mathrm{C}_{1} \mathrm{pyr}\right]^{+}$and $[\mathrm{FSI}]^{-}$and between $\mathrm{Li}^{+}$and [TFSI] $]^{-}$in solution. This later observation agrees with observations made from Fig. 4, highlighting a decrease of dissociated ionic species with increasing the Li[TFSI] concentration.

The collected self-diffusion coefficients were then fitted with an Arrhenius law over the investigated temperature range. Over this short temperature range, no evidence of the VTF law is observed, while each Arrhenius fit agrees perfectly with the experimental data (i.e. according to the $\mathrm{R}^{2}$ coefficient, which is approximately

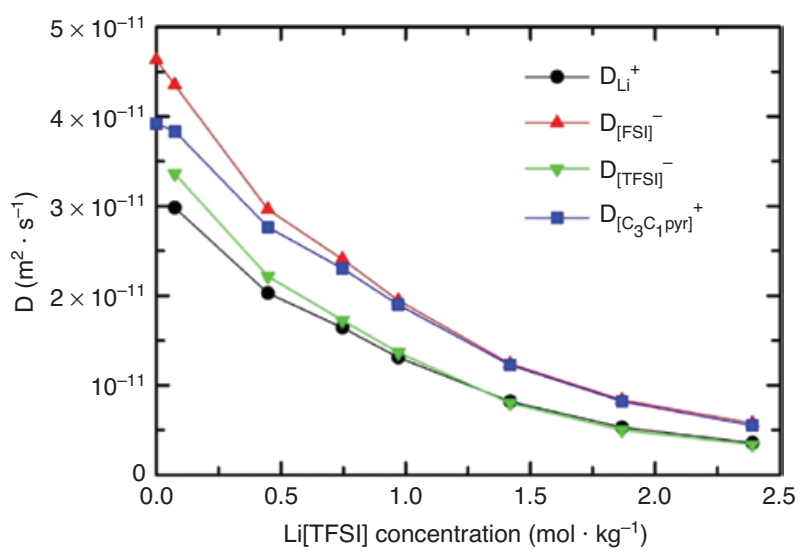

Fig. 5: Self-diffusion coefficients of each ion measured by PFG-NMR as a function of Li[TFSI] molality: $\bullet D_{\text {Lit }}, \Delta D_{[F S I]}{ }^{-}, \nabla D_{[T F S I]}{ }^{-}$, $\square \mathrm{D}_{[\text {[сзс1 } 1 \mathrm{pyr}]}^{+}$. 
0.99 in each case). The activation energy determined for each ion is then shown in Fig. 6 as a function of the Li[TFSI] molality.

The activation energies determined for $\mathrm{Li}^{+}$, $[\mathrm{TFSI}]^{-}$and $\left[\mathrm{C}_{3} \mathrm{C}_{1} \mathrm{pyr}\right]^{+}$are very similar over the whole concentration range. However, as soon as the Li[TFSI] concentration increases, the activation energy for the selfdiffusion of [FSI $]^{-}$species becomes much smaller than all others for a given Li-salt concentration, indicating a decoupling of its diffusive dynamics. As a result, stronger interactions are favoured between $\mathrm{Li}^{+}$and [TFSI] than between $\mathrm{Li}^{+}$and $[\mathrm{FSI}]^{-}$in solution. In fact, weaker interactions may explain why electrolytes containing [FSI] ${ }^{-}$anions have been the subject of constant interest [52]. Moreover, it is worth nothing that activation energy determined from self-diffusion data is very close to those obtained using viscosity vs. temperature (see Table $\mathrm{S} 7$ in the ESI).

Figure 7 shows the evolution of the $\Lambda_{\text {ion }} / \Lambda_{\mathrm{NMR}}$ ratio, which indicates to what extent and for which concentrations the diffusion coefficients determined by NMR reflect the motion of the charged species. In other words, a $\Lambda_{\mathrm{ion}} / \Lambda_{\mathrm{NMR}}$ value of approximately 1, corresponding to an ionicity of $100 \%$, is expected for a solution containing only dissociated ions and/or charged clusters. In the case of the neat IL, the $\Lambda_{\text {ion }} / \Lambda_{\mathrm{NMR}}$ value is 0.77 , which is close to values reported for 1-ethyl-3-methylimidazolium tetrafluoroborate and 1-butylpyridinium tetrafluoroborate [53]. This ratio is consistent with the fact that the neat IL has weak cation-anion interactions, leading to slightly different self-diffusion coefficients for $[\mathrm{FSI}]^{-}$and $\left[\mathrm{C}_{3} \mathrm{C}_{1} \mathrm{pyr}\right]^{+}$species in the absence of Li[TFSI] as shown in Fig. 5. However, the ionicity strongly decreases with the addition of lithium salt in

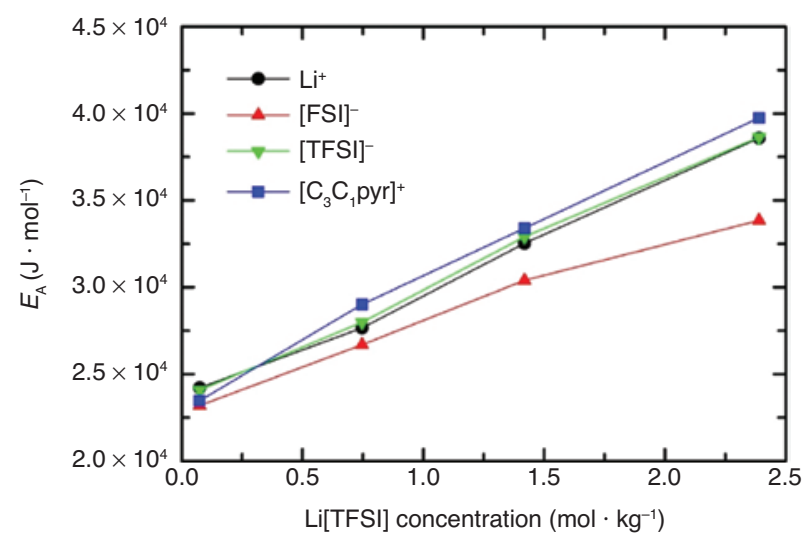

Fig. 6: Activation energies obtained with an Arrhenius fit of the self-diffusion coefficients measured by PFG-NMR over a range of temperatures from 27 to $67^{\circ} \mathrm{C}\left(\mathrm{\square}:\left[\mathrm{C}_{3} \mathrm{C}_{1} \text { pyr }\right]^{+}, \mathbf{\nabla}:[\mathrm{TFSI}]^{-}, \bullet\right.$ : $\left.\mathrm{Li}^{+}, \mathbf{\Delta}:[\mathrm{FSI}]^{-}\right)$.

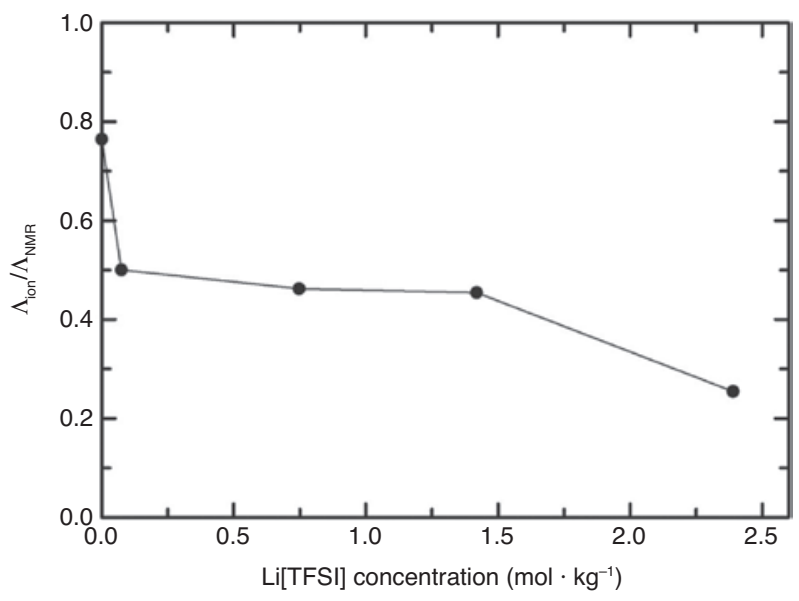

Fig. 7: Molar conductivity ratio $\left(\Lambda_{\text {ion }} / \Lambda_{\mathrm{NMR}}\right)$ plotted vs. Li[TFSI] concentration in solution. 
the IL reaching a $\Lambda_{\text {ion }} / \Lambda_{\mathrm{NMR}}$ ratio of approximately 0.5 by adding $0.075 \mathrm{~mol} \cdot \mathrm{kg}^{-1}$ of Li-salt in $\left[\mathrm{C}_{3} \mathrm{C}_{1}\right.$ pyr][FSI]. As shown in Fig. 7, this ratio remains almost constant within a wide range of Li[TFSI] concentrations up to $1.419 \mathrm{~mol} \cdot \mathrm{kg}^{-1}$, meaning that these solutions exhibit similar ionicity values. However, a further addition of Li salt in the solution induces a clear decrease in the $\Lambda_{\mathrm{ion}} / \Lambda_{\mathrm{NMR}}$ ratio (ionicity) and a decrease in the Walden product of the solution, as depicted in Figs. 4 and 7 by comparing data reported at 1.419 and $2.389 \mathrm{~mol} \cdot \mathrm{kg}^{-1}$. These observations are in excellent agreement with those reported by Yoon et al. [17] on the impact of the Li[FSI] concentration in $\left[\mathrm{C}_{3} \mathrm{C}_{1} \mathrm{pyr}\right][\mathrm{FSI}]$ on the ionicity of their solutions. The decreases observed on both the Walden product and ionicity (i.e. $\Lambda_{\text {ion }} / \Lambda_{\mathrm{NMR}}$ ratio) could be related to an increase in the number of undissociated salts or of less conductive ionic aggregates in solution, which cause an increase in viscosity and a decrease of the conductivity of the mixtures. This behaviour could be related to the observations made by comparing the self-diffusion coefficients of each ion involved in our mixtures as a function of Li[TFSI] concentration (Fig. 5), showing that stronger interactions are expected between $\left[\mathrm{C}_{3} \mathrm{C}_{1} \text { pyr }\right]^{+}$and $[\mathrm{FSI}]^{-}$than between $\left[\mathrm{C}_{3} \mathrm{C}_{1} \text { pyr }\right]^{+}$and $[\mathrm{TFSI}]^{-}$a contrario of $\mathrm{Li}^{+}$which seems to interact more strongly with [TFSI $]^{-}$than $[\mathrm{FSI}]^{-}$.

To examine this phenomenon in detail, interactions between $\mathrm{Li}^{+}$and $[\mathrm{FSI}]^{-}$or $[\mathrm{TFSI}]^{-}$in solutions was probed by HOESY experiments, which highlight the molecular proximity between interacting ions. In our case, both ${ }^{7} \mathrm{Li}$ to ${ }^{19} \mathrm{~F}$ and ${ }^{19} \mathrm{~F}$ to ${ }^{7} \mathrm{Li}$ transfer was successful, as shown in Fig. 8.

The heteronuclear intermolecular Overhauser effect is rather weak and depends upon the proximity of ions, the strength of their interactions, the local dynamics affecting the dipolar interactions and the relaxation times of each spin [54]. As observed for both electrolytes containing 0.448 and $1.419 \mathrm{~mol} \cdot \mathrm{kg}^{-1}$ of Li[TFSI] dissolved in $\left[\mathrm{C}_{3} \mathrm{C}_{1}\right.$ pyr] $[\mathrm{FSI}]$, the transferred signal is always weaker for $[\mathrm{FSI}]^{-}$compared to that expected due to the abundance in the samples. Therefore, this effect is likely a confirmation of the self-diffusion activation energies observed because regardless of the direction chosen for the magnetization transfer, strong associations between $\mathrm{Li}^{+}$and [TFSI] ${ }^{-}$(which lead to magnetization transfer by the Overhauser effect) are observed, while a weaker association and a smaller Overhauser transfer is observed for [FSI $]^{-}$with the $\mathrm{Li}^{+}$cation than for [TFSI] $]^{-}$.

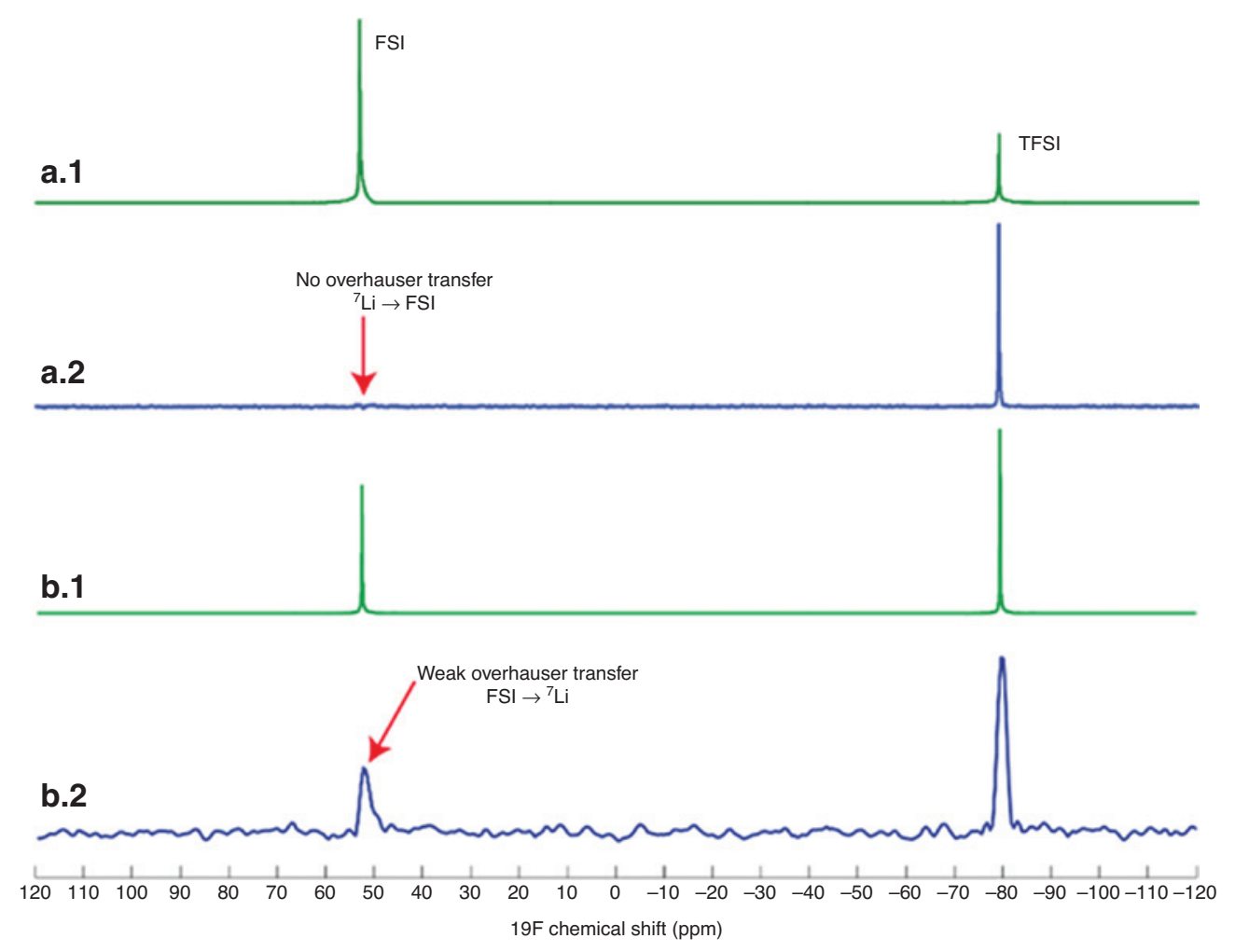

Fig. 8: Comparison between the $1 \mathrm{D}^{19} \mathrm{~F}$ NMR spectra (a.1 and b.1) and the HOESY spectra (a.2 and b.2) for Li[TFSI] concentrations of $0.448 \mathrm{~mol} \cdot \mathrm{kg}^{-1}$ (a.1 and a.2) and $1.419 \mathrm{~mol} \cdot \mathrm{kg}^{-1}$ (b.1 and b.2) at room temperature. 


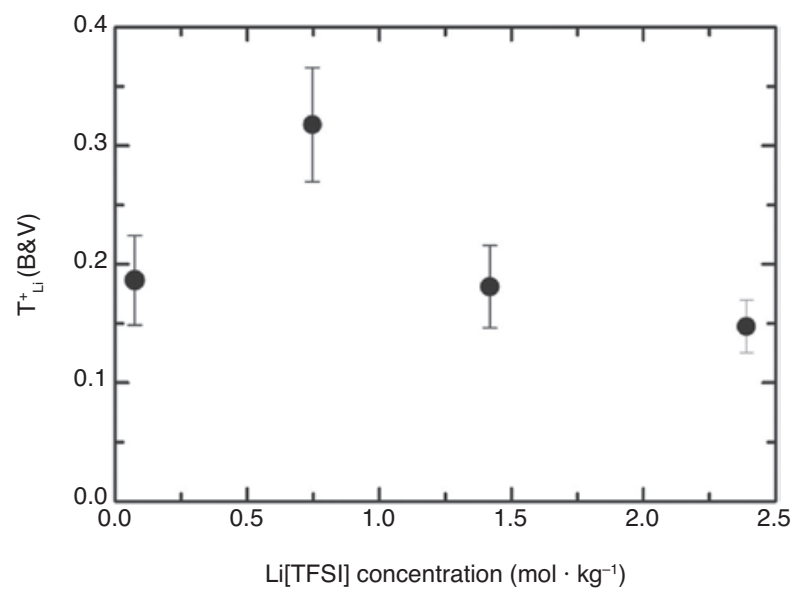

Fig. 9: Transference number of $\mathrm{Li}^{+}$determined by the Bruce and Vincent method as a function of Li[TFSI] concentration.

\section{Transference number}

The transference numbers for different salt concentrations using the Bruce and Vincent method are shown in Fig. 9 (with error bars). The transference numbers vary from 0.18 to 0.16 as the Li[TFSI] concentration increases. In Fig. 9, $\mathrm{T}_{\mathrm{Li}+}$ increases and then decreases when reaching a salt concentration of approximately $0.747 \mathrm{~mol} \cdot \mathrm{kg}^{-1}$. However, a maximum $\mathrm{T}_{\mathrm{Li}+}$ value is observed by using both methods for a Li salt concentration of approximately $0.747 \mathrm{~mol} \cdot \mathrm{kg}^{-1}$. This observation agrees with results from $\left[\mathrm{C}_{3} \mathrm{C}_{1}\right.$ pyr $][\mathrm{FSI}]+\mathrm{Li}[\mathrm{FSI}]$ blends published by Yoon et al. [17] and by Seki et al. [55].

\section{Structure and sigma profile of selected salts and ions}

The 3D structures, surface charge distributions and COSMO volumes of all investigated ions and salts are shown in Table 2. In this table, we report the more stable conformations of isolated [TFSI $]^{-}$and [FSI] ${ }^{-}$anions and $\mathrm{Li}^{+}$and $\left[\mathrm{C}_{3} \mathrm{C}_{1} \text { pyr }\right]^{+}$cations as well as all ion pair species formed by combining all of these ions. Additionally, using the optimized structure for each salt, the ion pair dissociation energy, $\Delta E_{d}$, was then calculated using Eq. 9 and by following the methodology reported by Scheers et al. [56]:

$$
\Delta E_{d}=\left(E_{\text {cation }}+E_{\text {anion }}\right)-E_{\text {ion pair }}
$$

As expected, and as shown in Table 2, in the case of $\mathrm{Li}^{+}\left(16.2099 \AA^{3}\right)$, the positive charge is solely localized on the $\mathrm{Li}$ atom (from $-0.034 \mathrm{e} \cdot \AA^{-2}$ to $-0.031 \mathrm{e} \cdot \AA^{-2}$ ); therefore, this cation has stronger Coulombic and hydrogen bonding interactions with selected anions than with the $\left[\mathrm{C}_{3} \mathrm{C}_{1} \mathrm{pyr}\right]^{+}$cation. The weaker interaction between selected anions and $\left[\mathrm{C}_{3} \mathrm{C}_{1} \mathrm{pyr}\right]^{+}$is also due to the increased size of the cation (193.3840 $\left.\AA^{3}\right)$; its sigma surface shows that the charge is mainly located on groups close to the nitrogen atom and contains two main regions, one for the polar region-hydrogen bonding donor site of this ion, located from $-0.013 \mathrm{e} \cdot \AA^{-2}$ to $-0.010 \mathrm{e} \cdot \AA^{-2}$, and one for the apolar alkyl chain of the cation, located from $-0.010 \mathrm{e} \cdot \AA^{-2}$ to $0.010 \mathrm{e} \cdot \AA^{-2}$. The presence of the apolar alkyl chain group suggests a stronger contribution from van der Waals interactions and a cohesive energy-inducing weaker interaction between $\left[\mathrm{C}_{3} \mathrm{C}_{1} \mathrm{pyr}\right]^{+}$and the selected anions compared to the interactions expected with the $\mathrm{Li}^{+}$cation, for example. Furthermore, as shown in Table 2, regardless of the anion selected, the ion pair dissociation energy of $\left[\mathrm{C}_{3} \mathrm{C}_{1}\right.$ pyr]-based ILs is always lower than that obtained for Li-salts, showing a clear decrease in the energy required to dissociate ions in solution due to the selection of $\left[\mathrm{C}_{3} \mathrm{C}_{1} \mathrm{pyr}\right]^{+}$rather than $\mathrm{Li}^{+}$. According to Table 2, the screening charge of the selected anions is more delocalized on the surface of $\left.{ }^{-T F S I}\right]^{-}$than $[\mathrm{FSI}]^{-}$. However, for a polarization charge higher than 0.01 , the weakest cation-anion interactions 
Table 2: Structure, abbreviation, COSMO volume and sigma profile of each selected ion and salt.

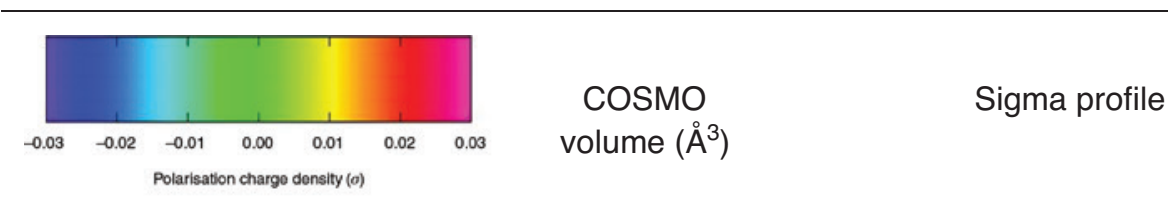

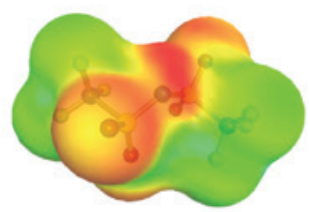

$[\mathrm{TFSI}]^{-}$

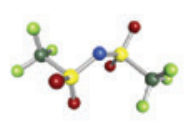

$219.6735 \AA^{3}$

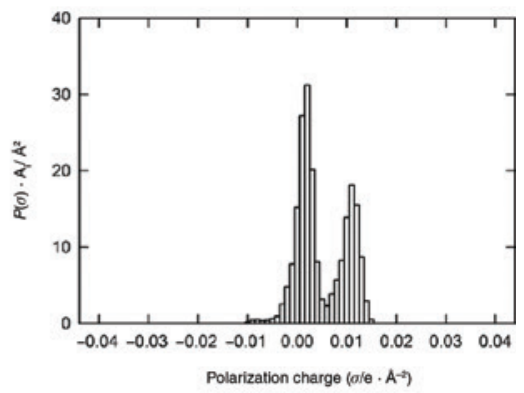

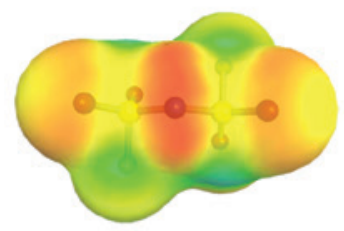

$[\mathrm{FSI}]^{-}$

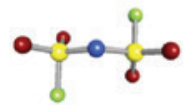

$139.6922 \AA^{3}$

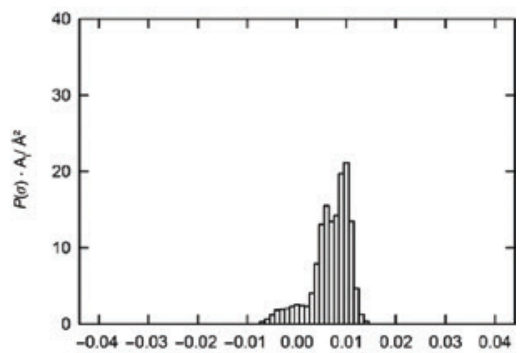

Polarization charge ( $\left.\sigma / \mathrm{e} \cdot \mathrm{A}^{-2}\right)$

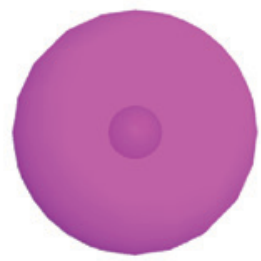

$\mathrm{Li}^{+}$

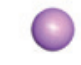

$16.2099 \AA^{3}$

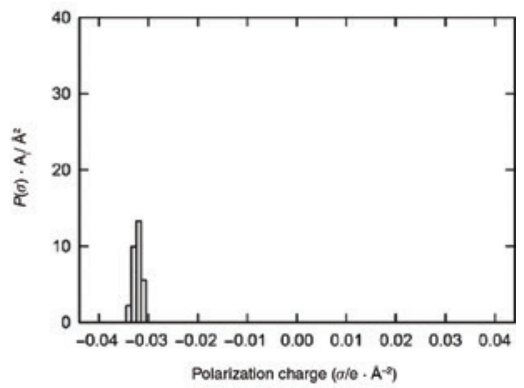

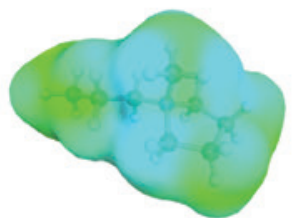

$\left[\mathrm{C}_{3} \mathrm{C}_{1} \text { pyr }\right]^{+}$

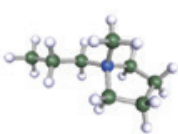

$193.3840 \AA^{3}$

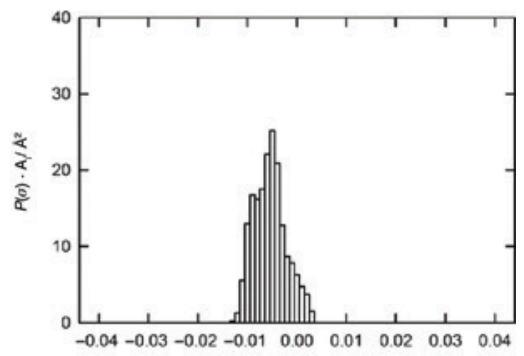

Polarization charge $(a / \theta \cdot A-7)$ 
Table 2 (continued)

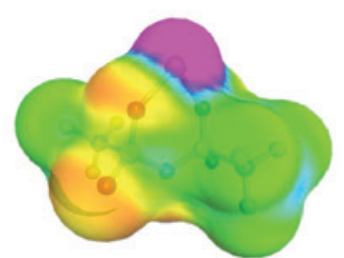

Li[TFSI] $\Delta E_{\mathrm{d}}=595.5 \mathrm{~kJ} \cdot \mathrm{mol}^{-1}$

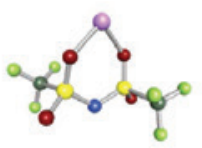

$226.9953 \AA^{3}$

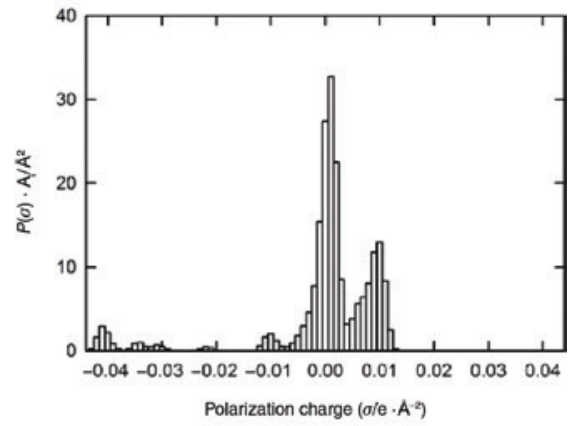

$\mathrm{Li}[\mathrm{FSI}]$

$\Delta E_{\mathrm{d}}=583.2 \mathrm{~kJ} \cdot \mathrm{mol}^{-1}$

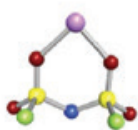

$146.4895 \AA^{3}$

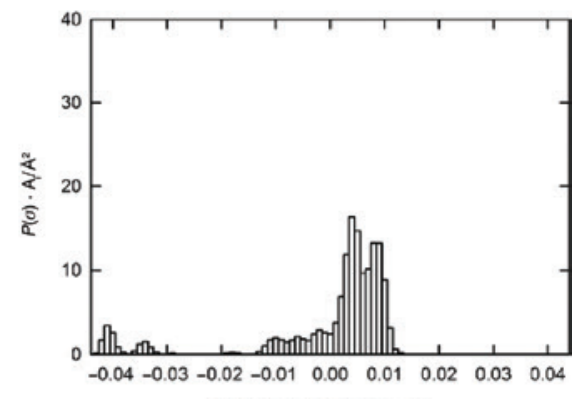

Polarization charge $\left(o / \mathrm{e} \cdot \mathrm{A}^{2}\right)$

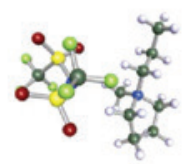

$422.1723 \AA^{3}$

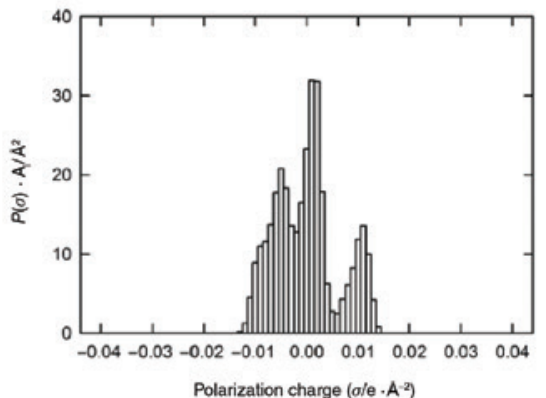

$\left[\mathrm{C}_{3} \mathrm{C}_{1} \mathrm{pyr}\right][\mathrm{TJSI}]$
$\Delta E_{\mathrm{d}}=299.0 \mathrm{~kJ} \cdot \mathrm{mol}^{-1}$

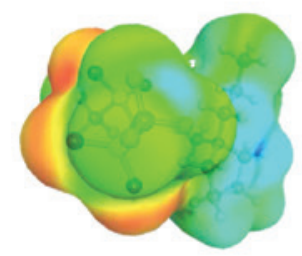

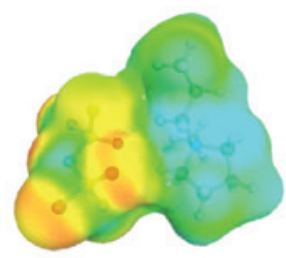

$\left[\mathrm{C}_{3} \mathrm{C}_{1} \mathrm{pyr}\right][\mathrm{FSI}]$ $\Delta E_{\mathrm{d}}=295.3 \mathrm{~kJ} \cdot \mathrm{mol}^{-1}$

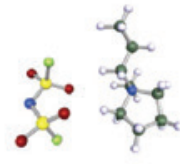

$342.6771 \AA^{3}$

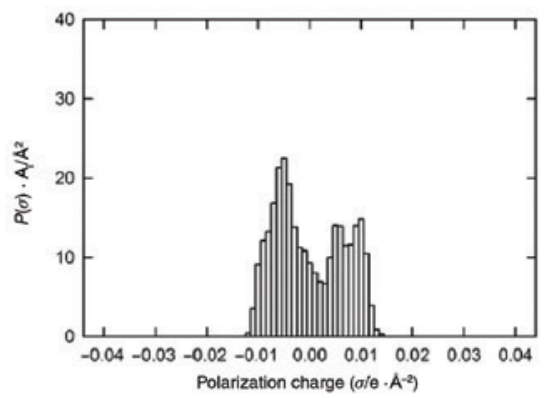


may be expected by selecting [TFSI] $]^{-}$than [FSI]- due to the larger volume of [TFSI] ${ }^{-}$(219.6735 $\AA^{3}$ vs. 139.6922 $\AA^{3}$ ). Furthermore, the charge of the sigma surface of [TFSI] ${ }^{-}$is less concentrated and spread over a larger area of the anion compared to that of [FSI] ${ }^{-}$. The sigma profile shows a large region of the charge densities around zero, which represents van der Waals-type interactions $\left(-0.01\right.$ and $\left.+0.01 \mathrm{e} \cdot \AA^{-2}\right)$ driven by the presence of the $\mathrm{CF}_{3}$ group. However, by depicting the population of charge for polarization charges higher than $+0.01 \mathrm{e} \cdot \AA^{-2}$ for both anions, [TFSI] ${ }^{-}\left(45.868 \AA^{2}\right)$ can clearly provide a stronger hydrogen bonding donor site than [FSI] $^{-}(19.798$ $\AA^{2}$ ), and therefore, [TFSI $]^{-}$anions appear to have stronger interactions than [FSI $]^{-}$with selected cations. This reduction in the interaction of [FSI ${ }^{-}$and the cation could also be due to charge delocalization, which involves all atoms on its surface including $\mathrm{F}$. This observation agrees with the ion pair dissociation energy trend, which shows a stronger interaction between selected cations and [TFSI] ${ }^{-}$than with [FSI] $]^{-}$, thus leading to a more structured salt and resulting in an increase of highly associated and correlated ions in solution by selecting $[\mathrm{TFSI}]^{-}$rather than $[\mathrm{FSI}]^{-}$. For example, the ion pair dissociation energy is found to be approximately $595.5 \mathrm{~kJ} \cdot \mathrm{mol}^{-1}$ and $583.2 \mathrm{~kJ} \cdot \mathrm{mol}^{-1}$ in the case of Li[TFSI] and Li[FSI] salts, respectively. Both energies are in excellent agreement with those reported by Scheers et al. (i.e. $592 \mathrm{~kJ} \cdot \mathrm{mol}^{-1}$ and $577 \mathrm{~kJ} \cdot \mathrm{mol}^{-1}$ for Li[TFSI] and Li[FSI] salts, respectively) [56]. Furthermore, structures presented herein are in excellent agreement with those also reported by these authors [56]. In each case, a bidentate configuration between $\mathrm{Li}^{+}$and two oxygen atoms in the selected anion is the most stable, along with a $\mathrm{Li}^{+}-\mathrm{O}$ distance of approximately $1.811 \AA$ and to $1.821 \AA$ for Li[TFSI] and Li[FSI], respectively. A similar trend is also reported for the interactions between $\left[\mathrm{C}_{3} \mathrm{C}_{1} \mathrm{pyr}\right]^{+}$and selected anions because the interactions between [TFSI $]^{-}$and $\left[\mathrm{C}_{3} \mathrm{C}_{1} \text { pyr }\right]^{+}$seem to be stronger $\left(\Delta E_{d}=299.0 \mathrm{~kJ} \cdot \mathrm{mol}^{-1}\right)$ than those between $[\mathrm{FSI}]^{-}$and $\left[\mathrm{C}_{3} \mathrm{C}_{1} \mathrm{pyr}\right]^{+}\left(\Delta E_{d}=295.3 \mathrm{~kJ} \cdot \mathrm{mol}^{-1}\right)$ even if both interactions are weaker than those observed with the selected Li-salts. This result is in excellent agreement with differences observed between the transport properties of these ILs because $\left[\mathrm{C}_{3} \mathrm{C}_{1} \mathrm{pyr}\right][\mathrm{FSI}]$ has a higher ionicity than $\left[\mathrm{C}_{3} \mathrm{C}_{1}\right.$ pyr $][\mathrm{TFSI}]$. Interestingly, the difference in the ion pair dissociation energies between Li[TFSI] and Li[FSI] $\left(\Delta \Delta E_{d}=12.3 \mathrm{~kJ} \cdot \mathrm{mol}^{-1}\right)$ is higher than that observed between the two ILs $\left(\Delta \Delta E_{d}=3.7 \mathrm{~kJ} \cdot \mathrm{mol}^{-1}\right)$, indicating that by mixing Li[TFSI] and $\left[\mathrm{C}_{3} \mathrm{C}_{1}\right.$ pyr $][\mathrm{FSI}]$, stronger interactions between $\mathrm{Li}^{+}$and $[\mathrm{TFSI}]^{-}$and between $\left[\mathrm{C}_{3} \mathrm{C}_{1} \text { pyr }\right]^{+}$ and [TFSI] ${ }^{-}$than other ion-ion associations may be expected. This observation is in excellent agreement with conclusions drawn herein from reported NMR results. COSMOthermX was then used to compute the contact statistics between species to further investigate changes in the structures and interactions of selected ions in solution. Figure 10 shows the species contact probability between ions in solutions as a function of the Li[TFSI] mole fraction over the whole composition range. Interestingly, one can see that whatever the Li[TFSI] composition in solution, the [TFSI] $]^{-} \mathrm{Li}^{+}$contact probability is always higher than that of $[\mathrm{FSI}]^{-}-\mathrm{Li}^{+}$. Similarly, the $[\mathrm{FSI}]^{-}$anion seems to interact preferentially with $\left[\mathrm{C}_{3} \mathrm{C}_{1} \mathrm{pyr}\right]^{+}$than with $\mathrm{Li}^{+}$in solution over the whole composition range. This result could be related to the difference in ion pair dissociation energies between each individual salt investigated herein as well as the weaker interactions between $\mathrm{Li}^{+}$and [FSI] ${ }^{-}$observed during the HOESY experiments. Furthermore, the addition of Li[TFSI] in $\left[\mathrm{C}_{3} \mathrm{C}_{1} \mathrm{pyr}\right][\mathrm{FSI}]$ does not lead to favourable interactions between all ions in solution except those already existing from former salts (i.e. in Li[TFSI] and in $\left.\left[\mathrm{C}_{3} \mathrm{C}_{1} \mathrm{pyr}\right][\mathrm{FSI}]\right)$. In summary, by combining computational and experimental results one may conclude that the number of undissociated salts $\left(\left[\mathrm{C}_{3} \mathrm{C}_{1} \mathrm{pyr}\right][\mathrm{FSI}]\right.$ and Li[TFSI $]$ ) or of less conductive cations... anions aggregates of $\mathrm{Li}^{+} \ldots[\mathrm{TFSI}]^{-}$and $\left[\mathrm{C}_{3} \mathrm{C}_{1} \mathrm{pyr}\right]^{+} \ldots[\mathrm{FSI}]^{-}$in solution increases with the Li-salt concentration explaining the decrease in ionicity reported in Fig. 7 when Li[TFSI] is added in solution, the effect of the Li-salt concentration on the self-diffusion coefficients of each ion measured by PFG-NMR (Fig. 5), and the Overhauser transfer between $\mathrm{Li}^{+}$and each anion (Fig. 8).

\section{Performance of Li-ion batteries}

The cyclability of Li/NMC cells with $\left[\mathrm{C}_{3} \mathrm{C}_{1}\right.$ pyr] $[\mathrm{FSI}]$ - Li[TFSI] mixtures at charge/discharge rates of $\mathrm{C} / 10$ and $1 \mathrm{C}$ is plotted in Fig. 11. The cell exhibited a discharge capacity of 144 and $101 \mathrm{mAh} \cdot \mathrm{g}^{-1} \mathrm{at} \mathrm{C} / 10$ and $1 \mathrm{C}$ discharge rates, respectively by using the electrolyte containing $0.747 \mathrm{~mol} \cdot \mathrm{kg}^{-1}$ of Li[TFSI] dissolved in $\left[\mathrm{C}_{3} \mathrm{C}_{1}\right.$ pyr] $\left.] \mathrm{FSI}\right]$. However, this cyclability performance is slightly lower than that expected from the values reported by Matsui 
a
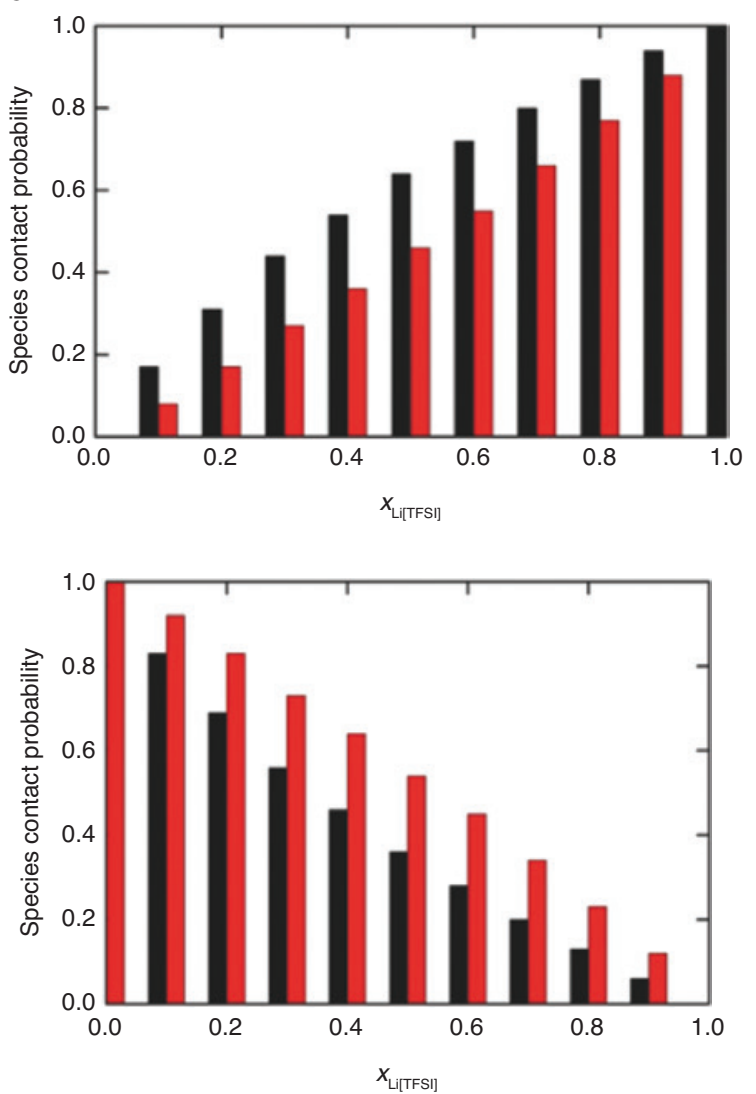

b
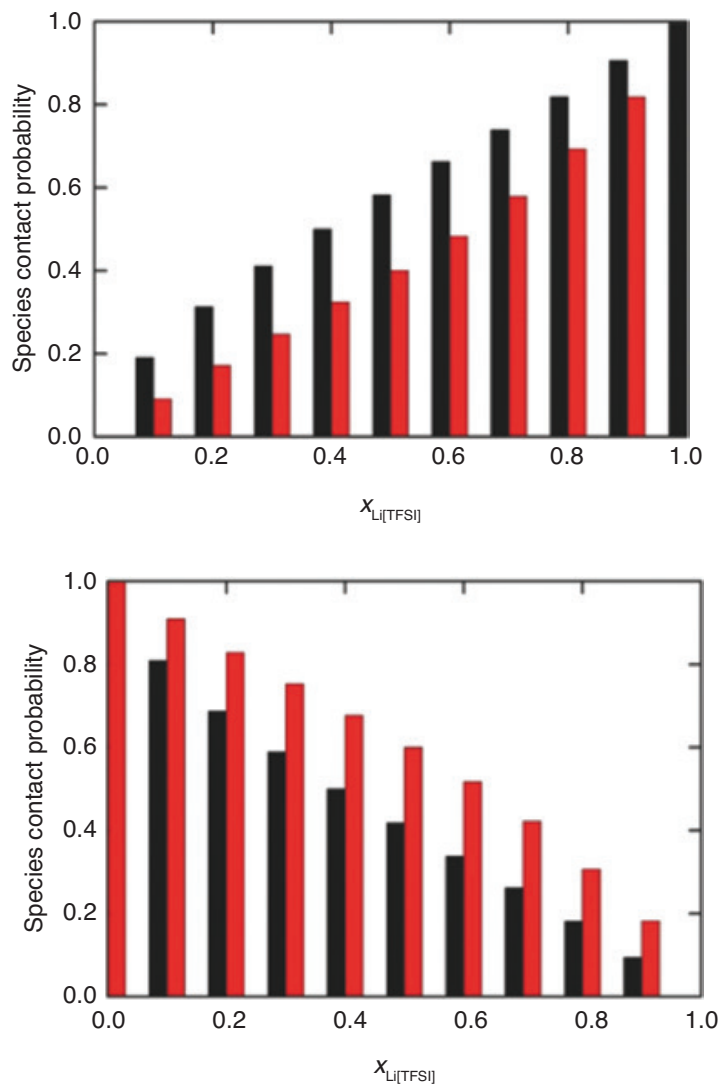

Fig. 10: Species contact probability (\%) between: (a) Li+ (black bars) or $\left[\mathrm{C}_{3} \mathrm{C}_{1} \text { pyr] }{ }^{+} \text {(red bars) with [TFSI] }\right]^{-}$(top) or with [FSI] $]^{-}$ (bottom); (b) [TFSI] $]^{-}$(black bars) or [FSI]- (red bars) with $\mathrm{Li}^{+}$(top) or with $\left[\mathrm{C}_{3} \mathrm{C}_{1}\right.$ pyr] ${ }^{+}$(bottom) as a function of the Li[TFSI] mole fraction.

et al. using an electrolyte based on the 1-ethyl-3-methylimidazolium bis(fluorosulfonyl)imide ([C $\mathrm{mim}][\mathrm{FSI}])$ mixed with Li[FSI] [57]. Indeed, the authors of this study reported a specific capacity of $163 \mathrm{mAh} \cdot \mathrm{g}^{-1}$. This relatively high value of capacity can be reasonably attributed to the lower viscosity of [ $\left.\mathrm{C}_{2} \mathrm{mim}\right][\mathrm{FSI}]$. Moreover, and as expected, we observed a decrease in the specific capacity with increasing the $\mathrm{C}$ rate. However, the battery still delivers around $70 \%$ of its initial capacity (i.e. capacity at $\mathrm{C} / 10$ ) when it is charged and discharged at $1 \mathrm{C}$. As shown in Fig. 11b, the specific capacity at $\mathrm{C} / 20$ remains constant with the increase of salt concentration. Therefore, the effect of the increase of the viscosity (and the decrease of conductivity) on the specific capacity is negligible at this slow rate. However, by increasing the $C$ rate (Fig. 11c), a decrease in the specific capacity is visible when the Li-salt molality is below $0.5 \mathrm{~mol} \cdot \mathrm{kg}^{-1}$. As shown in Fig. 11c, a discharge capacity of $113 \mathrm{mAh} \cdot \mathrm{g}^{-1}$ was reached for the electrolyte containing $0.075 \mathrm{~mol} \cdot \mathrm{kg}^{-1}$ of Li[TFSI] in [C $\left.{ }_{3} \mathrm{C}_{1} \mathrm{pyr}\right][\mathrm{FSI}$, while higher and almost constant specific capacities were observed by increasing the salt concentration. A further increase of the $\mathrm{C}$ rate leads to drastic capacity fading (Fig. 11d). However, results shown in Fig. 11c clearly highlight a concentration threshold at approximately $0.747 \mathrm{~mol} \cdot \mathrm{kg}^{-1}$ of $\mathrm{Li}[\mathrm{TFSI}]$ in $\left[\mathrm{C}_{3} \mathrm{C}_{1} \mathrm{pyr}\right][\mathrm{FSI}$, where the impact of the charge/discharge rate on the cell capacity is less distinct. Notably, this concentration also corresponds to the maximum $\mathrm{Li}^{+}$transference number as a function of Li[TFSI] concentration in solution (see Fig. 9). Likewise the transport properties, one can appreciate that the Li[TFSI] concentration greatly affects the electrochemical performance of the cell. Similar findings have been reported by Yoon et al. [17] on a Li/ $\mathrm{LiCoO}_{2}$ cell using the $\left[\mathrm{C}_{3} \mathrm{C}_{1} \mathrm{pyr}\right][\mathrm{FSI}]+\mathrm{Li}[\mathrm{FSI}]$ electrolyte. Indeed, these authors noted a drastic improvement in cell capacity by increasing the Li[FSI] concentration in solution even when both the fluidity and ionic conductivity of the electrolyte decrease. 
a

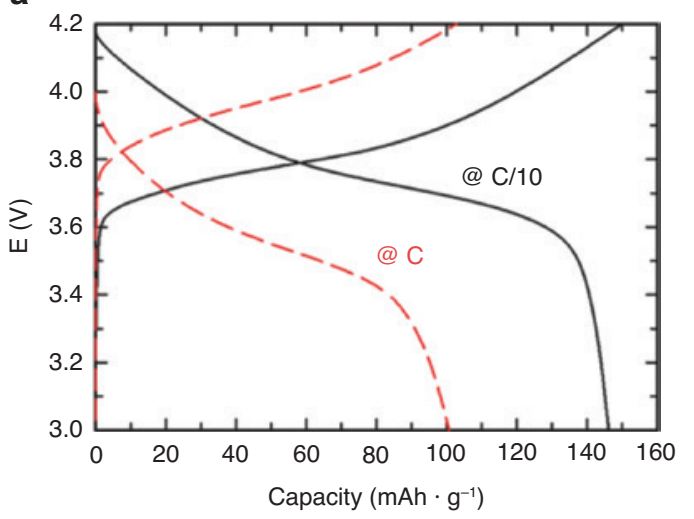

C

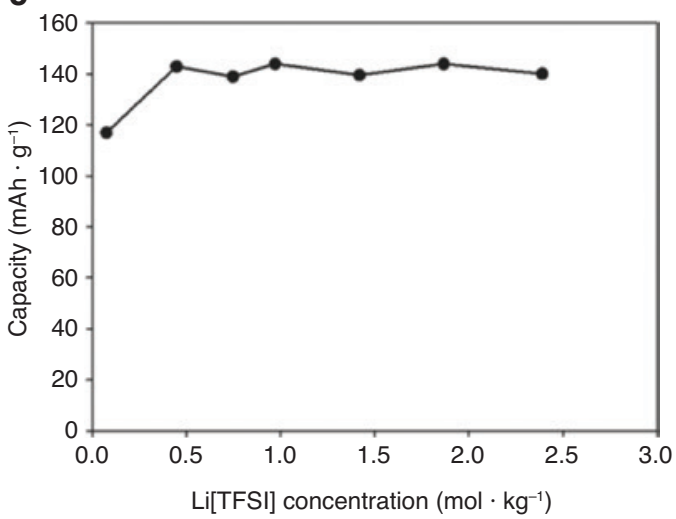

b

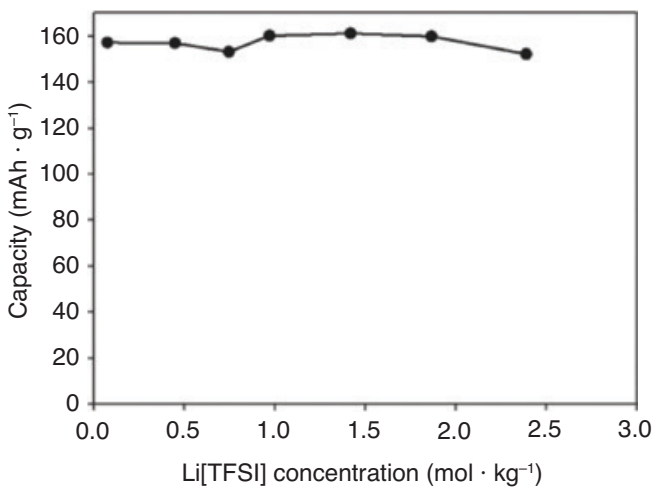

d

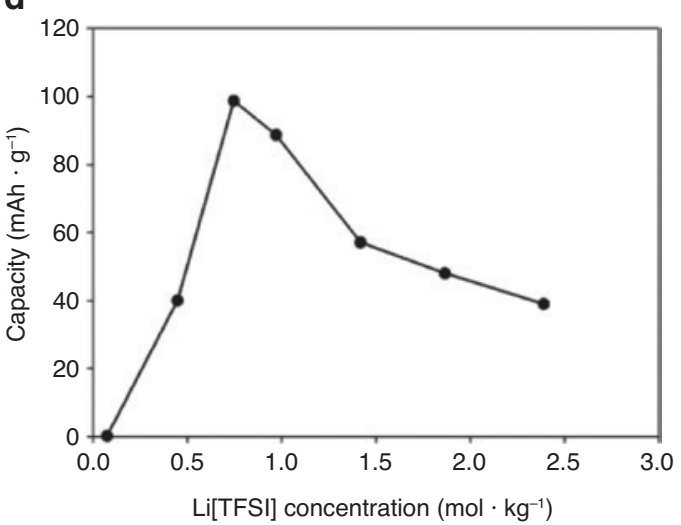

Fig. 11: Charge and discharge profiles (a) at C/10 and $1 \mathrm{C}$ of the $\mathrm{Li} / \mathrm{NMC}$ batteries using the electrolyte based on $0.747 \mathrm{~mol} \cdot \mathrm{kg}^{-1}$ $\mathrm{Li}[\mathrm{TFSI}]$ in $\left[\mathrm{C}_{3} \mathrm{C}_{1}\right.$ pyr] [FSI]. Discharge capacity vs. the Li[TFSI] concentration at C/20 (b), C/10 (c), and $1 \mathrm{C}(\mathrm{d})$.

To clearly establish the role of the Li concentration on the cell performances, a second battery configuration was tested. The cell was made using an LTO anode instead of lithium foil in order to eliminate the contribution of $\mathrm{Li}$ electrode contribution to the $\mathrm{Li}^{+}$concentration during cell charging and discharging. Figure 12a and $\mathrm{b}$ show the charge/discharge profile of the cell at $\mathrm{C} / 10$ and $\mathrm{C} / 2$ rates using electrolytes with two different Li[TFSI] concentrations (i.e. 0.448 and $1.419 \mathrm{~mol} \cdot \mathrm{kg}^{-1}$ ) in the $\left[\mathrm{C}_{3} \mathrm{C}_{1} \mathrm{pyr}\right][\mathrm{FSI}]$, respectively. At a low discharge rate, the cell showed a specific capacity of approximately 130 and $145 \mathrm{mAh} \cdot \mathrm{g}^{-1}$ for 0.448 and $1.419 \mathrm{~mol} \cdot \mathrm{kg}^{-1} \mathrm{Li}$ [TFSI] electrolytes, respectively. Moreover, an increase of the discharge rate of the cell leads to a great decrease in the specific capacity. Therefore, $40 \%$ of the initial capacity was achieved using the $1.419 \mathrm{~mol} \cdot \mathrm{kg}^{-1} \mathrm{Li}[\mathrm{TFSI}]$ electrolyte, while only $13 \%$ of the initial capacity was reached with the electrolyte containing $0.448 \mathrm{~mol} \cdot \mathrm{kg}^{-1} \mathrm{Li}[\mathrm{TFSI}]$ dissolved in $\left[\mathrm{C}_{3} \mathrm{C}_{1}\right.$ pyr][FSI]. Such observations suggest that the Li[TFSI] concentration greatly impacts the cell performance. Moreover, the cell is not able to deliver any capacity (or negligible) when the electrolyte containing $0.075 \mathrm{~mol} \cdot \mathrm{kg}^{-1} \mathrm{Li}$ [TFSI] in $\left[\mathrm{C}_{3} \mathrm{C}_{1} \mathrm{pyr}\right][\mathrm{FSI}]$ is used, even at a low discharge rate (see Fig. 12c and d). This result contrasts with that obtained in the Li/NMC cell because this later cell still delivered a measurable capacity even at a low Li salt concentration (e.g. $0.075 \mathrm{~mol} \cdot \mathrm{kg}^{-1}$ ) in solution, as shown in Fig. 11c and d.

In addition, the cell performance vs. Li[TFSI] concentration reveals an optimum specific capacity at approximately $1.419 \mathrm{~mol} \cdot \mathrm{kg}^{-1} \mathrm{Li}[\mathrm{TFSI}]$ in $\left[\mathrm{C}_{3} \mathrm{C}_{1} \mathrm{pyr}\right][\mathrm{FSI}]$ (Fig. 12d). However, this concentration threshold is two times higher than that observed using a lithium anode-based cell (Fig. 11d). These results highlight that the salt nature and concentration not only influence diffusion and lithium transport in the bulk but also greatly impact battery performances.

During battery operation, cations and anions migrate to the negative and positive electrodes to maintain a local electroneutrality, which leads to an ionic concentration gradient in the electrolyte and an increase in 
a

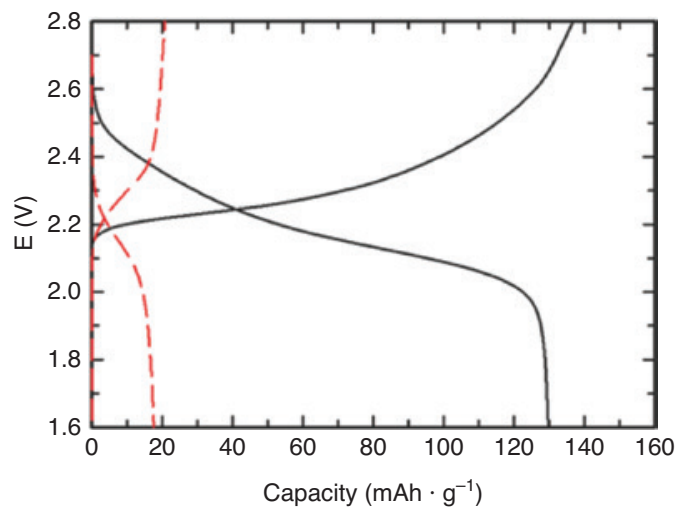

C

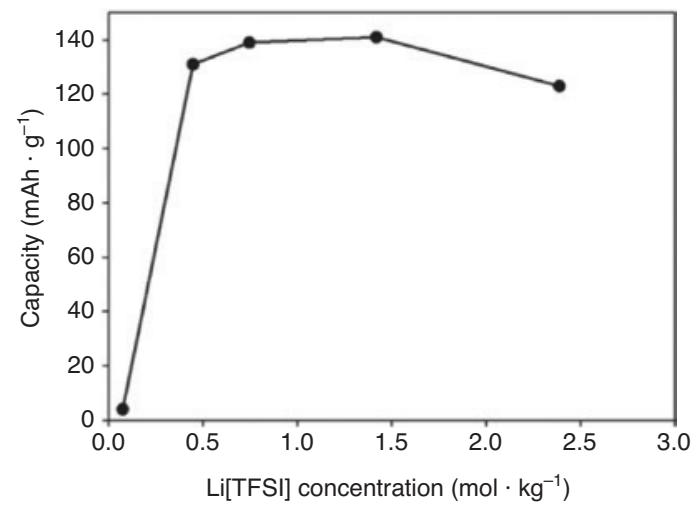

b

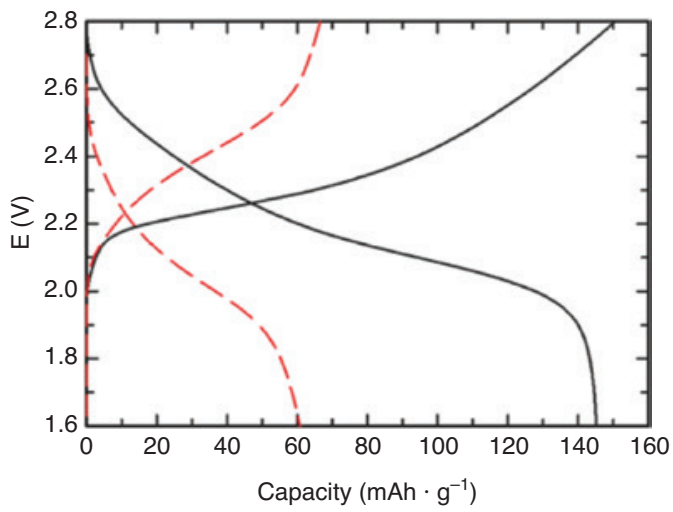

d

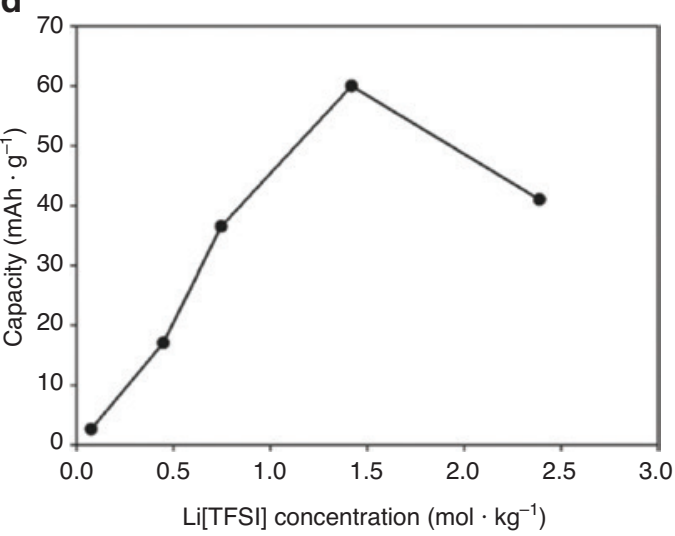

Fig. 12: Charge and discharge profile at C/10 (black) and C/2 (red) of LTO/NMC batteries using electrolytes of (a) $0.448 \mathrm{~mol} \cdot \mathrm{kg}^{-1}$ and (b) $1.419 \mathrm{~mol} \cdot \mathrm{kg}^{-1}$ of Li[TFSI] in [ $\mathrm{C}_{3} \mathrm{C}_{1}$ pyr][FSI]. Discharge capacity vs. the Li[TFSI] concentration at: (c) C/10 and (d) C/2.

the concentration polarization of the battery. This polarization increases with the charging/discharging rate and depends on the salt concentration. At a low salt concentration, LTO/NMC exhibits a negligible capacity even at low charge/discharge rates (Fig. 12c and d). However, the situation is different in the Li/NMC-type battery with a full capacity at $\mathrm{C} / 20$ and $\mathrm{C} / 10$ even at low concentrations of Li-salt in solution (Fig. 11c and d). However, the capacity was negligible at $1 \mathrm{C}$ but increases with salt concentration. In conclusion, both systems reveal a specific electrolyte composition for the optimal operation of the batteries. The optimal concentration of Li[TFSI] is higher in the LTO/NMC system, which may be due to contributions from the charge transfer resistance and solid diffusion within the LTO, which could increase the overall battery polarization; however, those conditions are not true for the Li/NMC configuration.

\section{Conclusions}

During this work, different electrolytes containing the 1-propyl-1-methylpyrrolidinium bis[fluorosulfonyl] imide ([ $\mathrm{C}_{3} \mathrm{C}_{1}$ pyr $\left.][\mathrm{FSI}]\right)$ IL mixed with the lithium bis[(trifluoromethyl)sulfonyl]imide (Li[TFSI]) were prepared as a function of the lithium salt composition in solution. These mixtures have been then characterized in term of their viscosity, ionic conductivity, density as function of temperature.

Pulsed Field Gradient Nuclear Magnetic Resonance PEG-NMR method was used to independently measure the self-diffusion coefficients of the anions and the cations in these mixtures. Interestingly, the self-diffusion coefficients of all ions clearly indicate strong interactions between $\left[\mathrm{C}_{3} \mathrm{C}_{1} \mathrm{pyr}\right]^{+}$and $[\mathrm{FSI}]^{-}$and between $\mathrm{Li}^{+}$and $[\mathrm{TFSI}]^{-}$in solution especially when the $\mathrm{Li}[\mathrm{TFSI}]$ molality is higher than $0.971 \mathrm{~mol} \cdot \mathrm{kg}^{-1}$. Such 
observation agrees with that made based on the ionicity of these electrolytes as function of Li[TFSI] concentration. Furthermore, the temperature dependences on the collected self-diffusion coefficients of all ions in solution have been fitted according to Arrhenius equation to determine then their activation energy. These data showed that the activation energy of [FSI]- is more strongly affected by the Li[TFSI] concentration in the solution than other ions in solution. In other words, [FSI $]^{-}$anion has a lower activation energy than all other species in the solution $\left.\left(\left[\mathrm{C}_{3} \mathrm{C}_{1} \mathrm{pyr}\right]^{+}, \mathrm{Li}^{+} \text {, and [TFSI }\right]^{-}\right)$indicating a decoupling of its diffusive dynamics. One can therefore suspect stronger interactions between $\mathrm{Li}^{+}$and [TFSI] $]^{-}$than between $\mathrm{Li}^{+}$and [FSI] ${ }^{-}$in the solution. The stronger interaction between $\mathrm{Li}^{+}$and [TFSI]- has been further confirmed thanks to HOESY experiments. This conclusion has been also strengthened thorough ab initio and COSMO-RS calculations. Briefly, these calculations showed that whatever the Li[TFSI] concentration in the solution, the [TFSI] $]^{-} \mathrm{Li}^{+}$contact probability is always higher than that of $[\mathrm{FSI}]^{-}-\mathrm{Li}^{+}$, while $[\mathrm{FSI}]^{-}$anion seems to interact preferentially with $\left[\mathrm{C}_{3} \mathrm{C}_{1} \mathrm{pyr}\right]^{+}$.

As the main goal of this study was to establish a relationship between the transport properties and the battery performances of an electrolyte based on an ionic liquid and a lithium salt containing different anions ([FSI] $]^{-}$and [TFSI] $]^{-}$, the selected electrolytes have been then used to cycle Li-ion batteries. The key finding of this study is, regardless the battery configuration (anode and cathode composition), that the specific capacity strongly depends on the salt concentration. More interestingly, an increase of the $\mathrm{C}$ rate clearly highlights a concentration optimum or threshold, which would allow optimal battery operations. Therefore, transference number and specific capacity determination led to the same conclusion: i.e. an increase of the salt concentration allows a better performance of the battery until to reach an optimum concentration of Li salt dissolved in the $\left[\mathrm{C}_{3} \mathrm{C}_{1}\right.$ pyr $][\mathrm{FSI}]$-based IL.

Funding: The authors like to gratefully acknowledge the funding from the regional council "Région Centre" for the DESLIS and $\mu \mathrm{BaGs}$ projects. The authors are indebted to the IR-RMN-THC FR3050 CNRS for the spectrometer time access and the financial support of the NMR experiments.

\section{References}

[1] K. Liu, Y. Liu, D. Lin, A. Pei, Y. Cui. Sci. Adv. 4, eaas9820 (2018).

[2] A. Mauger, C. M. Julien, A. Paolella, M. Armand, K. Zaghib. Mater Sci. Eng. R Rep. 134, 1 (2018).

[3] M. Wang, Y. Tang. Adv. Energy Mat. 8, 1703320 (2018).

[4] N. Chen, H. Zhang, L. Li, R. Chen, S. Guo. Adv. Energy Mat. 8, 1702675 (2018).

[5] Q. Yang, Z. Zhang, X.-G. Sun, Y.-S. Hu, H. Xing, S. Dai. Chem. Soc. Rev. 47, 2020 (2018).

[6] T. Rüther, M. Kanakubo, A. S. Best, K. R. Harris. Phys. Chem. Chem. Phys. 19, 10527 (2017).

[7] S. Murphy, F. Ivol, A. R. Neale, P. Goodrich, F. Ghamouss, C. Hardacre, J. Jacquemin. ChemPhysChem 19, 3226 (2018).

[8] Y. Matsui, M. Yamagata, S. Murakami, Y. Saito, T. Higashizaki, E. Ishiko, M. Kono, M. Ishikawa. J. Power Sources 279, 766 (2015).

[9] R. Kerr, D. Mazouzi, M. Eftekharnia, B. Lestriez, N. Dupré, M. Forsyth, D. Guyomard, P. C. Howlett. ACS Lett. 2, 1804 (2017).

[10] S.-J. Kang, K. Park, S.-H. Park, H. Lee. Electochim. Acta 259, 949 (2018).

[11] Q. Zhou, W. A. Henderson, G. B. Appetecchi, M. Montanino, S. Passerini. J. Phys. Chem. B 112, 13577 (2008).

[12] A. Guerfi, S. Duchesne, Y. Kobayashi, A. Vijh, K. Zaghib. J. Power Sources 175, 866 (2008).

[13] A. I. Bhatt, A. S. Best, J. H. Huang, A. F. Hollenkamp. J. Electrochem. Soc. 157, A66 (2010).

[14] M. Shimizu, H. Usui, H. Sakaguchi. Phys. Chem. Chem. Phys. 18, 5139 (2016).

[15] Y. Umebayashi, H. Hamano, S. Seki, B. Minofar, K. Fujii, K. Hayamizu, S. Tsuzuki, Y. Kameda, S. Kohara, M. Watanabe. J. Phys. Chem. B 115, 12179 (2011).

[16] F. Castiglione, A. Famulari, G. Raos, S. V. Meille, A. Mele, G. B. Appetecchi, S. Passerini. J. Phys. Chem. B 118, 13679 (2014).

[17] H. Yoon, P. C. Howlett, A. S. Best, M. Forsyth, D. R. MacFarlane. J Electrochem. Soc. 160, A1629 (2013).

[18] R. Younesi, G. M. Veith, P. Johansson, K. Edström, T. Vegge. Energy Environ. Sci. 8, 1905 (2015).

[19] A. Fernicola, F. Croce, B. Scrosati, T. Watanabe, H. Ohno. J. Power Sources 174, 342 (2007).

[20] V. Aravindan, J. Gnanaraj, S. Madhavi, H. K. Liu. Chem. Eur. J. 17, 14326 (2011).

[21] D. R. MacFarlane, N. Tachikawa, M. Forsyth, J. M. Pringle, P. C. Howlett, G. D. Elliott, J. H. Davis, M. Watanabe, P. Simon, C. A. Angell. Energy Environ. Sci. 7, 232 (2014).

[22] Y. Jin, S. Fang, J. Zhang, Z. Zhang, K. Yu, J. Song, L. Yang, S.-I. Hirano. Ind. Eng. Chem. Res. 53, 2860 (2014). 
[23] V. Chaudoy, F. Ghamouss, J. Jacquemin, J. C. Houdbert, F. Tran-Van. J. Solution Chem. 44, 769 (2015).

[24] M. Kerner, N. Plylahan, J. Scheers, P. Johansson. Phys. Chem. Chem. Phys. 17, 19569 (2015).

[25] K. R. Seddon, A. Stark, M. J. Torres. Pure Appl. Chem. 72, 2275 (2000).

[26] P. Husson, L. Pison, J. Jacquemin, M. F. Costa Gomes. Fluid Phase Equilibr. 294, 98 (2010).

[27] W. J. R. Gilbert, J. Safarov, D. L. Minnick, M. A. Rocha, E. P. Hassel, M. B. Shiflett. J. Chem. Eng. Data 62, 2056 (2017).

[28] C. Amman, P. Meier, A. E. Merbach. J. Magn. Reson. 46, 319 (1982).

[29] D. H. Wu, A. D. Chen, C. S. Johnson. J. Magn. Reson. Ser. A 115, 260 (1995).

[30] A. Jerschow, N. Müller. J. Magn. Reson. 125, 372 (1997).

[31] D. Bankmann, R. Giernoth. Prog. Nucl. Magn. Reson. Spectrosc. 51, 63 (2007).

[32] R. Ahlrichs, M. Bär, M. Häser, H. Horn, C. Kölmel. Chem. Phys. Lett. 162, 165 (1989).

[33] F. Weigend, M. Häser. Theor. Chem. Acc. 97, 331 (1997).

[34] F. Weigend, M. Häser, H. Patzelt, R. Ahlrichs. Chem. Phys. Lett. 294, 143 (1998).

[35] A. D. Becke. Phys. Rev. A. 38, 3098 (1988).

[36] C. Lee, W. Yang, R. G. Parr. Phys. Rev. B 37, 785 (1988).

[37] S. Grimme. J. Comput. Chem. 27, 1787 (2006).

[38] M. Anouti, Y. R. Dougassa, C. Tessier, L. El Ouatani, J. Jacquemin. J. Chem. Thermodyn. 50, 71 (2012).

[39] F. Ghamouss, A. Brugere, J. Jacquemin. J. Phys. Chem. C 118, 14107 (2014).

[40] E. Coadou, P. Goodrich, A. R. Neale, L. Timperman, C. Hardacre, J. Jacquemin, M. Anouti. ChemPhysChem. 17, 3992 (2016).

[41] A. Tagiuri, K. Z. Sumon, A. Henni, K. Zanganeh, A. Shafeen. Fluid Phase Equilib. 375, 324 (2014).

[42] K. Matsumoto, Y. Okamoto, T. Nohira, R. Hagiwara. J. Phys. Chem. C 119, 7648 (2015).

[43] S. Seki, S. Tsuzuki, K. Hayamizu, Y. Umebayashi, N. Serizawa, K. Takei, H. Miyashiro. J. Chem. Eng. Data 57, 2211 (2012).

[44] K. Hayamizu, S. Tsuzuki, S. Seki, K. Fujii, M. Suenaga, Y. Umebayashi. J. Chem. Phys. 133, 194505 (2010).

[45] G. B. Appetecchi, M. Montanino, M. Carewska, M. Moreno, F. Alessandrini, S. Passerini. Electrochim. Acta 56, 1300 (2011).

[46] T. Makino, M. Kanakubo, T. Umecky, A. Suzuki, T. Nishida, J. Takano. J. Chem. Eng. Data 57, 751 (2012).

[47] H. Yoon, A. S. Best, M. Forsyth, D. R. MacFarlane, P. C. Howlett. Phys. Chem. Chem. Phys. 17, 4656 (2015).

[48] M. Moreno, E. Simonetti, G. B. Appetecchi, M. Carewska, M. Montanino, G.-T. Kim, N. Loeffler, S. Passerini. J. Electrochem. Soc. 164, A6026 (2017).

[49] M. Kunze, S. Jeong, G. B. Appetecchi, M. Schönhoff, M. Winter, S. Passerini. Electrochim. Acta 82, 69 (2012).

[50] C. A. Angell, Y. Ansari, Z. Zhao. Faraday Discuss. 154, 9 (2012).

[51] C. Schreiner, S. Zugmann, R. Hartl, H. J. Gores. J. Chem. Eng. Data 55, 1784 (2009).

[52] I. A. Shkrob, T. W. Marin, Y. Zhu, D. P. Abraham. J. Phys. Chem. C 118, 19661 (2014).

[53] A. Noda, K. Hayamizu, M. Watanabe. J. Phys. Chem. B 105, 4603 (2001).

[54] P.-A. Martin, E. Salager, M. Forsyth, L. A. O’Dell, M. Deschamps. Phys. Chem. Chem. Phys. 20, 13357 (2018).

[55] S. Seki, Y. Ohno, H. Miyashiro, Y. Kobayashi, A. Usami, Y. Mita, N. Terada, K. Hayamizu, S. Tsuzuki, M. Watanabe. J. Electrochem. Soc. 155, A421 (2008).

[56] J. Scheers, E. Jónsson, P. Jacobsson, P. Johansson. Electrochem. 80, 1825 (2012).

[57] Y. Matsui, S. Kawaguchi, T. Sugimoto, M. Kikuta, T. Higashizaki, M. Kono, M. Yamagata, M. Ishikawa. Electrochem. 80, 808 (2012).

Supplementary Material: The online version of this article offers supplementary material (https://doi.org/10.1515/pac-2018-1006). 